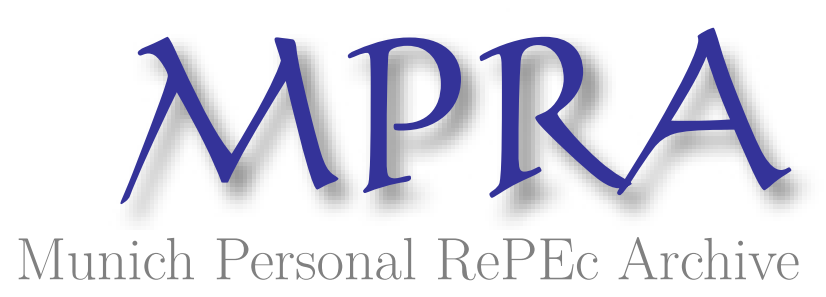

\title{
Measuring the effects of U.S. uncertainty and monetary conditions on EMEs' macroeconomic dynamics
}

Rivolta, Giulia and Trecroci, Carmine

Catholic University of the Sacred Heart, Milan, University of Brescia

1 April 2020

Online at https://mpra.ub.uni-muenchen.de/99403/

MPRA Paper No. 99403, posted 07 Apr 2020 14:05 UTC 


\title{
Measuring the effects of U.S. uncertainty and monetary conditions on EMEs' macroeconomic dynamics
}

\author{
Giulia Rivolta \\ Catholic University of the Sacred Heart, Milan \\ Carmine Trecroci ${ }^{1}$ \\ University of Brescia
}

1 April 2020

Abstract

We explore empirically the transmission of U.S. financial and macroeconomic uncertainty to emerging market economies (EMEs). We start by assuming that there are crucial differences between volatility and uncertainty, and between the latter and its shocks. With the help of Bayesian vector autoregressions, we first identify two measures of U.S. uncertainty shocks, which appear to explain the dynamics of output developments better than conventional volatility measures. Next, we find evidence that adverse shocks to U.S. aggregate uncertainty are associated with marked contractions in some EMEs' business cycles. However, we detect significant cross-country heterogeneity in the responses of EMEs' business cycles to U.S uncertainty shocks. We also find generalized declines in stock market values, which supports the socalled Global Financial Cycle hypothesis.

Keywords: Uncertainty, Monetary policy, Asset prices, Emerging markets.

JEL codes: $C_{11}, C_{32}, E_{44}, E_{52}, E_{5} 8, F_{3} 6$.

\section{Introduction}

Over the past three decades, several developing countries have witnessed ever-closer market integration within the global economy. As a result, the responses of their macroeconomic

\footnotetext{
${ }^{1}$ Corresponding author. Department of Economics and Management, University of Brescia, Via San Faustino 74/B, 25122 Brescia, carmine.trecroci@unibs.it.
} 
conditions to global fluctuations have become tighter. Existing research shows that deeper international interdependence between asset markets could result either from stronger structural transmission of business cycles fluctuations, or simply from larger shocks (see Bua and Trecroci 2019, for some empirical evidence). However, there is no clear-cut evidence as to the channels through which asset prices and macroeconomic conditions in emerging market economies (EMEs) react to developments originating in advanced countries. In principle, the international transmission of monetary and financial impulses may occur through observed changes in the term structure of local interest rates and in the market valuation of other assets. In practice, several realworld factors beyond the appreciation of the econometrician are likely to play a significant role in the propagation of shocks. One of them is aggregate uncertainty. In this paper, we identify shocks to U.S. aggregate uncertainty and measure their spillovers - of the macroeconomic and financial type - on EMEs' level of economic activity and key asset prices.

Money and uncertainty are inextricably linked. In a world of certainty, known, fixed relative prices allow production, consumption and investment to proceed along pre-arranged lines, so that the only service of money is as an inventory. In contrast, under uncertainty, the main function of money becomes to alleviate transaction costs. This close association is a first motive why we investigate the output impact of uncertainty jointly with money and liquidity conditions. Investors and consumers forecast future cash flows through some complex learning process that reflects uncertainty about their distributional properties. Cognitive limitations and/or shortage of degrees of freedom likely force agents to under-parameterize and frequently change their forecasting models. Accordingly, we compute estimates of U.S. uncertainty shocks under very general assumptions about the information set and that are fully endogenous with respect to the state of the economy.

Given the international prominence of the dollar and U.S. financial markets, U.S. monetary and financial developments tend to have a disproportionate global impact. Both the Great Financial Crisis started in 2007-8 and the so-called "taper tantrum", i.e., the market responses to changes in U.S. monetary and funding conditions in 2013-14, had significant impacts on EMEs' financial and macroeconomic dynamics (Cerutti et al. 2019). The dynamics of those and other events confirm that the propagation of U.S. impulses to other countries' economic activity and asset values is a function of several elements. The literature highlights three broad channels of transmission: exchange-rate variations, trade linkages and other monetary and financial interdependences (see 
for instance Ammer et al. 2016). For obvious reasons the latter provide for a swifter pass-through, although a particularly complex one to ascertain.

Several types of shocks could trigger more or less synchronized fluctuations in EMEs, mostly through changes in the external value of collateral assets. The DSGE model of Mendoza (2010) examines the implications of various shocks - including imported input prices, global interest rates and productivity shocks - for real activity. This evidence helps explain why the abrupt slowdowns or reversals of capital inflows observed in EMEs are often followed by financial stress, during which losses to net worth and tightening margins can also lead to co-movement. In a setting with multiple assets, risky asset prices might co-move (even though their cash flows are independently distributed) because they are exposed to the same funding liquidity constraints. Losses can also generate co-movement of assets held by common investors. Finding evidence of substantial financial spillovers of U.S. monetary policy on a global scale, Miranda-Agrippino and Rey (2020) argue: "U.S. monetary policy shocks induce comovements in the international financial variables that characterize the Global Financial Cycle" (see also Cerutti et al. 2019 and Jorda et al. 2019).

Macroeconomics conventionally equates risk (in particular lower-tail risk) with uncertainty and measures the former with volatility. However, we believe that it is empirically important to distinguish between volatility, which measures the dispersion of outcomes in a known distribution, and uncertainty. Both may affect macroeconomic and financial outcomes, in several ways. However, more than volatility, it is heteroskedasticity of shocks and fundamentals that may influence investors' and consumers' ability to identify the distribution of future payoffs. Forecasts of key market variables are, plausibly, the outcome of some complex learning process that reflects uncertainty. In turn, the latter is the conditional volatility of an event that is unforecastable from the perspective of economic agents. Therefore, we follow Jurado et al. (2015) and measure uncertainty as the standard error of the $n$-step-ahead forecast error. The fundamental processes of macroeconomic variables, whose drift rates depend on changes in investment opportunities, may drive the business cycle of open economies. As agents strive to learn the state of the global economy, the variance of their forecast errors fluctuates, thereby affecting consumption and investment choices, as well as their aggregate implications. Excess financial volatility during bad times, for example, might reflect - though not coincide with -a jump to higher uncertainty.

We study the joint impact of uncertainty shocks and U.S. funding conditions for the dynamics of economic activity and asset values of nine important emerging economies using quarterly data 
over the past four decades. Our analysis departs from most existing studies as we employ a novel combination of methodology and data that overcomes some well-known weaknesses of the existing evidence. Empirical work on this question should take into account crucial differences between volatility and uncertainty, and between the latter and its shocks. Therefore, our procedure involves two steps. First, we employ a Bayesian VAR model for the U.S. economy, including an indicator of aggregate U.S. uncertainty, to identify the structural shocks to uncertainty and to financial conditions. Second, we estimate a VAR model for each country, where, assuming that shocks to U.S.-based uncertainty could shape global developments, they enter as an exogenous regressor. We then assess the local, country-by-country effects of uncertainty shocks on macroeconomic aggregates and key asset valuations. As opposed to a panel approach, our procedure yields comprehensive evidence on the transmission mechanism and on country heterogeneity in the responses. For a preliminary hint of our evidence, in Figure 1 we plot the quarterly time series of the median of the shocks we obtain by alternatively inserting a financial (dashed black line) or a macroeconomic (continuous red line) uncertainty indicator in our Bayesian VAR for the U.S.. The chart also shows the demeaned (and rescaled) VIX real-time index of implied volatility of the S\&P 500 index and in shaded bars the NBER-dated periods in which the US economy was in recession. Negative values of the uncertainty shocks indicate an unexpected fall in uncertainty. Some key stylized facts emerge. The two uncertainty series are positively correlated, but the timings of peaks and troughs, as well as the volatility and persistence properties, exhibit a few differences, in relation to the VIX too. The Great Financial Crisis and in general the second part of the sample show more frequent and persistent uncertainty shocks, especially of the macro variety. In contrast, the simple volatility index is more persistent and it spikes with shorter lags in correspondence of downturns of economic activity.

Besides uncovering rich country-by-country dynamics, this study yields two main contributions to the debate. First, in contrast to most of the extant evidence, we detect significant cross-country differences in the responses of EMEs' business cycles to U.S. uncertainty shocks. We detect sizeable adverse effects of shocks to U.S. uncertainty on the level of economic activity in some EMEs, whereas in other countries the impact is less clear. Inflation, interest rates, credit aggregates and capital flows too react along quantitatively different lines: some economies seem more tightly connected with U.S. monetary and uncertainty developments than others. We thus confirm that EMEs' differences in macro-financial vulnerabilities or institutional arrangements (or both) may imply important heterogeneities in the exposure of local business cycles to international shocks. 
Furthermore, the equity valuations of most emerging countries we consider experience a significant and persistent correction. This evidence supports the hypothesis that U.S. aggregate uncertainty is an important driver of the so-called "Global Financial Cycle" (Miranda-Agrippino and Rey 2020).

The remainder of this study is structured as follows. The next Section provides a brief review of the evidence on the effects of US monetary policy and uncertainty on EMEs. Section 3 sets out the methodology and present estimation results. Section 4 concludes.

\section{Discussion of the literature}

Security prices embed a risk-premium component that depends on volatility and on the risk aversion of market participants. Both elements are time varying at the global and the local level. Therefore, risk premia are sensitive to revisions in market expectations of underlying business conditions. In turn, these stem from changes in the subjective probability distribution of macroeconomic risks and to the uncertainty surrounding those revisions. Indeed, it is increasingly clear that variations in risk premia have first-order impacts on economic activity (see Gilchrist and Zakrajsek 2012, for instance). Both the finance and macroeconomics literatures extensively show that first and second moments of key variables tend to display very different statistical properties across tranquil and crisis periods. Financial markets are characterized by low-uncertainty, noncrisis periods, infrequently interspersed by high-uncertainty intervals of severe stress. In measurement, situations in which we know both the future outcomes and their probability distribution are commonly classified as risk (more or less conventionally insurable). On the other hand, when events or outcomes are known but their probabilities are not, we are in the area of uncertainty (not easily insurable; Knight 1921).

The term "financial cycle" has recently gained centre ground in policy debates. It refers to the selfreinforcing interactions between perceptions of value and risk, risk-taking, and financing constraints (Borio 2014). The basic idea is that particularly favourable credit and monetary conditions prop up asset prices, which in turn drive up collateral valuations and therefore expand the amount of credit provided to the private sector, until the process goes into sharp reverse. The mutually reinforcing interdependence between funding conditions, market valuations and risks has tended to accompany and maybe cause long-term adverse macroeconomic effects. In theory, 
similarly to what happens in a closed-economy context for firms and households, the presence of various financial frictions might affect a country's net worth and its ability to borrow on the global markets. The relevance of imperfections is probably even stronger in an open-economy context, because funding flows are costlier to monitor and enforce and information asymmetries are greater, influencing access to international finance more than to domestic finance (Borio and Zhu 2012; Bruno and Shin 2015; Coimbra and Rey 2018). Both supply- and demand-side factors are likely to play important roles, although to a different extent in relation to local characteristics. For instance, the relevance of the so-called bank-lending channel varies across countries, and it might be higher in bank-dominated systems. In countries where the funding role of capital markets is relatively important, firms and households enjoy external finance alternatives, whereas in bankbased systems fewer options might exist. Shin (2012) and Rey (2015) highlight that changes in liquidity intermediated globally by banks (and interacting with U.S. monetary policy) can lead to more pronounced and synchronised national fluctuations. The magnitude of those variations seems to relate to countries' institutions and operational arrangements. For example, countries with market-based financial systems tend to exhibit greater cyclicality in leverage. As changes in leverage and liquidity affect the real economy, financial shocks can consequently have a greater real impact. From a methodological point of view, this calls for leaning towards single-country approaches, which is the way we proceed in this paper, as opposed to the pooled, panel-data analyses that are very common in the extant literature.

The research has so far primarily focused on uncertainty as a driver of economic fluctuations, mostly in the context of closed economies. Bloom (2014) is a recent survey of this literature, which offers some evidence of contractionary domestic effects of US uncertainty shocks (see also Bekaert et al. 2013). On the other hand, Ludvigson et al. (2019) find that macro uncertainty rises endogenously in response to real activity shocks, contributing strongly to its countercyclical behaviour.

Recently, uncertainty has entered the research into the international propagation of monetary and macroeconomic shocks. In general, international asset markets equate the flows of savings and investment at a global level. Monetary and financial shocks affect the relative prices of risky assets, which reflect the equalization of global investors' portfolio demands for domestic or foreign assets to the available stocks. Therefore, with low transaction costs, local asset prices may react to changes in portfolio weights triggered by global shifts in asset values, wealth, financial conditions, 
risk aversion and expectations. Indeed, macroeconomic models increasingly often include reduced-form risk premium shocks, and many contributions find that in fact they are relevant in explaining fluctuations of real activity (e.g., Christiano et al. 2014). Likewise, several studies identify proxies for macroeconomic uncertainty that tend to rise sharply at the onset of downturns (Jurado et al. 2015), while there is growing evidence that uncertainty itself might even cause them (Alessandri and Mumtaz 2019, Ludvigson et al. 2019).

Rey (2015) yields evidence of international implications of variation in a measure of U.S. risk aversion. It also provides key motivation for our paper, as it finds a significant correlation between US stock market volatility, as measured by the VIX, and global asset prices and credit flows (Cuaresma et al. 2020 corroborates these findings using a Bayesian VAR with factor stochastic volatility). An implication of these findings is that open-economy models should allow macro uncertainty to exert some effects on both real activity and asset values, which we do in our empirical specification.

The outsized international impact of U.S. monetary policy has been the object of several analyses. For instance, Dedola et al. (2017), lacoviello and Navarro (2019) and Mehrotra et al. (2019) identify sizeable interest rate spillovers from the United States on to advanced and emerging economies' macroeconomic aggregates. Early contributions have measured U.S. financial uncertainty shocks with the VIX or VXO. Other authors consider different notions, like policy uncertainty (Colombo 2013 and Caggiano et al. 2019). Recently, some works have focused on global uncertainty (e.g. Choi 2018, Bonciani and Ricci 2018, Ahir et al. 2018, and Castelnuovo 2019).

The contributions most closely related to ours are those analysing the spillovers of U.S. uncertainty shocks on emerging countries. Carrière-Swallow and Cespedes (2013) study the effects of an exogenous change in the VXO index on consumption and investments in advanced and EMEs countries, finding that the latter experience stronger contractionary outcomes. As we argued above, country-specific characteristics such as the quality of business institutions, the depth of the local financial sector, and the degree of financial dollarization influence the dynamic responses of local variables.

Choi (2018) studies the effects of VIX shocks on the U.S. and 18 emerging economies using twocountry VARs with block exogeneity. The results show that VIX shocks have recessionary effects on EME countries that are greater than on the U.S. and that financial frictions in credit markets act as the main propagation mechanism. Bhattarai et al. (2019) investigate the effects of identified VIX 
shocks on 18 emerging countries using a Bayesian panel-VAR and finding relevant financial and macroeconomic spillovers. We depart from this work in various respects. First, we do not rely on the VIX but on the Jurado et al. (2015) measures of uncertainty. Second, our time sample is longer. Third, we identify U.S. shocks through a richer model for the U.S. that controls also for financial factors. Fourth, we estimate separate models for the EMEs so that we do not impose any kind of homogeneity constraint on coefficients and responses across countries.

Empirical findings about the macroeconomic role of uncertainty depend on two key methodological choices: measuring uncertainty and identifying an uncertainty shock. Most of the existing literature has used the notions of volatility, risk aversion and uncertainty almost interchangeably. Therefore, most studies identify uncertainty by relying on proxies or a single time series, such as the implied or realized volatility of stock market returns, the cross-sectional dispersion of firm profits, stock returns, the cross-sectional dispersion of subjective (survey-based) forecasts, or the recurrence of certain "uncertainty-related" keywords in news publications. In most cases, the simple proxies directly enter a VAR model as an endogenous variable. Relevant examples are Bloom (2009), Caggiano et al. (2014), Basu and Bundick (2017) and Cesa-Bianchi et al. (2019), in which stock market volatility, realized or as implied in the prices of index options contracts, is used to proxy for uncertainty.

We crucially depart from this influential strand of the literature under two important respects. Our key premise is that agents do not know the true distribution of shocks and therefore they must use data to make inferences about it. This means that, although volatility and uncertainty might be related, they are distinct factors. The key hypothesis of this paper is that the arrival of new information and agents' uncertainty have defined implications on the valuation of macroeconomic risks. Agents engage in systematic learning, aimed at extracting and updating forecasts of risks to future cash flows. The main drawback of the volatility indicators employed in much of the existing literature is that their time variation may depend on market factors only partly related with agents' ability to identify the distribution of future cash flows, especially at the typical business-cycle frequency. In response to these problems, some authors construct uncertainty indicators starting from subjective or objective data; e.g. Bachmann et al. (2013) use business surveys and Baker et al. (2016) rely on newspaper coverage. Even though they seem useful to investigate some aspects related to volatility, these proxies too seem only loosely associated with a distinct notion of macroeconomic or financial uncertainty. To overcome this issue, Jurado et al. (2015) build 
composite macroeconomic and financial uncertainty indicators based on a rich dataset of both kinds of time series and show that they have strong real effects. Other authors argue that estimates from models with external uncertainty indicators may embed a generated-regressors bias that invalidate inference. Therefore, Carriero et al. (2018a), Alessandri and Mumtaz (2019) and Cuaresma et al. (2020) propose to measure both uncertainty and its effects in a single step within the same model. The latter paper identifies international uncertainty shocks as the joint volatility process that determines the dynamics of the variance-covariance matrix of the common factors in a large-scale Bayesian VAR.

We employ the composite indicators by Jurado et al. (2015). These measures better track at a business-cycle frequency the extent to which agents are uncertain about the true values of macroeconomic and financial variables, as well as of the model parameters employed to forecast them.

Our second departure from previous studies concerns the identification of uncertainty shocks. There is no clear consensus in the VAR literature on the appropriate identification strategy. This difficulty comes from the fact that in this area it is hard to find unambiguous theoretical restrictions to apply. Consequently, most contributions identify uncertainty shocks by relying on a recursive identification scheme implemented through Cholesky decomposition of the residuals' variancecovariance matrix, as for example in Bloom (2009) and Jurado et al. (2015). However, this approach disregards the possible presence of contemporaneous feedbacks between uncertainty and the other variables in the model. We believe this is particularly consequential for the tight relationship between funding conditions and uncertainty. Accordingly, Angelini et al. (2019), Carriero et al. (2018a) and Ludvigson et al. (2019) propose new identification strategies. In particular, to achieve set identification Ludvigson et al. (2019) impose constraints on the timing, magnitude and correlation among the shocks, but not on the impulse response functions as in the classical signrestrictions approach. They use shock-based constraints in which the uncertainty shock is required to satisfy some qualitative and quantitative restrictions connected to historical events and other constraints that require the shock to be correlated with some external variables. Their results show financial uncertainty as exogenous and macroeconomic uncertainty as endogenous. This approach presents some difficulty for the univocal identification of uncertainty shocks in large VAR systems, where one should at least check that the imposed restrictions do not yield series of other shocks with implausible features. Carriero et al. (2018a) and Angelini et al. (2019) exploit 
heteroskedasticity to achieve identification in a VAR setup. In contrast to Ludvigson et al. (2019), Carriero et al (2018a) find evidence that financial uncertainty is endogenous while macroeconomic uncertainty is exogenous. Finally, Angelini et al. (2019) argue that both macroeconomic and financial uncertainty are exogenous, whereas Redl (2020) extracts estimates of macro and financial uncertainty for 11 advanced economies.

External variables are used by Carriero et al (2015) and Piffer and Podstawski (2018), who apply the methodology described in Stock and Watson (2018) to identify uncertainty shocks. This method still relies on some proxy for uncertainty, which is assumed to be exogenous to the economy, and neglects possible two-way feedbacks between uncertainty and the business cycle.

Carriero et al. (2015) test the performance of recursive and proxy SVARs with data generated from a DSGE model; they also reconsider the analysis of Bloom (2009) using the VXO index as indicator variable for financial uncertainty and a dummy variable as external instrument to identify shocks. Both exercises show that estimates from recursive VAR models are likely downward-biased, while models based on external proxies produce impulse responses close to the underlying DSGE responses. In turn, Piffer and Podstawski (2018) merge set identification with proxy-SVAR to identify both uncertainty and news shocks².

The interdependence between uncertainty and financial conditions and its relevance for identification is an important issue to take into account. Indeed, recent studies consider financial frictions as powerful means of propagation of uncertainty shocks in the economy (Popp and Zhang 2016, Alessandri and Mumtaz 2019). For this reason, Caldara et al. (2016) identify uncertainty and financial shocks in a VAR model using a penalty function that assumes that the shocks of interest generate the largest increase in an uncertainty measure over a certain horizon 3 .

\section{Methodology and estimation}

\footnotetext{
${ }^{2}$ The proxy for uncertainty is the change in the price of gold around some unanticipated events that potentially affected uncertainty and were orthogonal to other macroeconomic shocks.

3 This approach boils down to a Cholesky decomposition when the penalty function only considers the impact of the shocks. They estimate several different models in which a measure of uncertainty is coupled with the excess bond premium to capture financial shocks. These two measures are placed first in the VAR model and their order is alternated to evaluate the effect of different orderings.
} 
This section describes the models and methodologies used in our analysis, and then presents our main results. As discussed, among others, by Miranda-Agrippino and Rey (2020), Obstfeld (2020) and Gourinchas et al. (2019), the U.S. dollar's role in the international monetary system as a premium reserve currency, a funding currency, an invoicing currency for trade, and a vehicle currency in the foreign exchange market makes it a primary channel of shocks to liquidity. The yields of dollar assets likely incorporate a liquidity premium that rises in periods of high uncertainty and financial stress, when the risk-taking attitude of investors and intermediaries recedes. Conversely, during low uncertainty, risk-on intervals, the demand and market valuation of non-U.S. assets increases. Thus, we might see U.S. yields and spreads as related to uncertainty on international capital markets; we account for this in the specification of our empirical models. However, we leave aside the important topic of the possible feedback impact from other economies' response onto the US cycle.

Our procedure involves two steps. First, we estimate for the U.S. economy a Bayesian VAR model that includes a composite indicator of uncertainty, and we use it to characterize the structural shocks to financial conditions and aggregate uncertainty. In order to obtain the shocks to financial and macroeconomic uncertainty, we alternatively employ two variants of the VAR model for the U.S.. Second, we build a Bayesian VAR model for each country, where, assuming that U.S. uncertainty shapes global uncertainty, its shocks enter as an exogenous regressor. We therefore investigate the local effects of uncertainty shocks by analysing the impulse response function and historical decomposition. Our choice of quarterly data strikes an equilibrium between the relatively high-frequency changes in financial variables and uncertainty and the lower frequency of typical business-cycle fluctuations. Besides, data availability is a constraining issue for EMEs4.

\subsection{The U.S. model}

Our key hypothesis about uncertainty is that at a business-cycle frequency the continuous arrival of new information and agents' uncertainty interact in ways that measures of stock market volatility cannot fully capture. We assume that agents engage systematically in a learning activity on the state of the economy. This leads to the extraction and update of forecasts of future values of variables and parameters relevant for their choices. Consequently, to measure U.S. uncertainty we use, alternatively, two monthly composite indicators, one for financial uncertainty and another

\footnotetext{
${ }^{4}$ In particular, official capital flows figures from the IMF are only available at quarterly frequency.
} 
for macroeconomic uncertainty, both introduced by Jurado et al. (2015). These proxies aggregate, respectively, 147 financial time series and 132 macroeconomic variables. Caldara et al. (2016) find that these measures give economic uncertainty the maximal role in explaining business cycle fluctuations. Our identification strategy implies that they are exogenous for the US economy. We saw above that the evidence about the endogeneity of uncertainty is mixed: according to Carriero et al. (2018b), macroeconomic uncertainty is exogenous and financial uncertainty is endogenous, whereas Ludvigson et al. (2019) find the opposite. Overall, even though their results seem at odds with each other, both studies recommend that uncertainty indicators should not be ordered last in a VAR, as this would cloud the measures of their true impact on the economy. Accordingly, Angelini et al. (2019) show that both indicators are exogenous.In our specification, we order the uncertainty proxy first in the VAR and then apply zero short-run restrictions with the Cholesky decomposition of the variance-covariance matrix of the residuals. This choice has a twofold motivation. First, the shocks we retrieve can be interpreted as structural if uncertainty is predetermined with respect to the other variables in the system. Secondly, the impulse responses we deriveare the generalized response functions described in Koop et al. (1996) and Pesaran and Shin (1998), i.e. they are the difference between a conditional and an unconditional projection of the VAR model, where the conditioning set is the shock to the variable of interest. Furthermore, our implied impulse responses are consistent with results by other studies that employ less parsimonious identification schemes.

We write our reduced-form VAR model in companion form as

$$
Y_{t}=B Y_{t-1}+\varepsilon_{t}, \quad \varepsilon_{t} \sim N(0, \Sigma)
$$

We estimate the model through Bayesian inference and follow the approach of Banbura et al. (2010), which allows to deal with high-dimensionality VARs. The rationale behind the large BVARs is that by using informative priors it is possible to shrink the likely over-parameterized model toward a more parsimonious specification and thus reduce estimation uncertainty. Therefore, the choice on the informativeness of the priors is crucial. Here, we follow Giannone et al. (2015), i.e., we select the appropriate degree of shrinkage by treating priors' hyper-parameters as additional unknown parameters, formulating a prior over them and maximizing the marginal likelihood to derive their posterior values. We use a Normal-Inverse-Wishart distribution as prior for the coefficient and the variance-covariance matrix of the errors:

$$
\sum \sim I W(\Psi, d)
$$




$$
\beta \mid \Sigma \sim N(b, \Sigma \otimes \Omega)
$$

Here $\Psi, d, b$ and $\Omega$ are functions of a set of hyperparameters $\gamma$. The conditional prior for the VAR coefficients $b$ allows to achieve Bayesian shrinkage by combining three prior densities: the Minnesota, the sum-of-coefficients and dummy-initial-observation priors. The Minnesota prior assumes that the limiting form of each VAR equation is a random walk with drift. The sum-ofcoefficients prior and the dummy-initial-observation prior are necessary to account for unit root and cointegration. The tightness of these priors is determined by the three hyperparameters $\lambda, \mu_{1}$ and $\delta$, respectively. All the hyperparameters are treated as unknown so that the model has a hierarchical structure. Computationally, the algorithm features a Metropolis step to draw the vector of hyperparameters and then, conditional on the value of $\gamma$, the VAR parameters are drawn from their posterior, which too is the Normal-Inverse-Wishart. This algorithm generates 20.000 draws, of which we discard the first 10,000 as burn-in and use the last 10,000 for inference. Further details on the prior specification and estimation procedure are in Giannone et al. (2015).This framework allows to estimate the VAR in levels, with variables expressed in annualized terms; we include 5 lags of the endogenous variables.

Our modelling strategy assumes that several factors, well beyond any single measure of the interest rate, jointly influence financial conditions and, through them, economic activity. Accordingly, our VAR system for the U.S. includes the uncertainty composite indicator, associated to either financial or macroeconomic uncertainty, plus six U.S.-specific variables and two international indices. The U.S. quantities are real GDP and GDP-deflator based inflation, the excess bond premium of Gilchrist and Zakrajzek (2012), real stock prices based on the S\&P5Oo index and the CPI, the ratio to GDP of credit to the private sector and the 1-year government bond yield. To control for global drivers of economic fluctuations we also include the CRB index of commodity prices and the nominal effective exchange rate.

In line with some of the extant investigations, we include the excess bond premium to account for the evolution of funding conditions. It is a measure of investors' risk appetite in the corporate bond market that captures the cyclical changes in the relationship between measured default risk and credit spreads. Its rise signals heightened perceived risk aversion and uncertainty. The literature finds that it significantly affects economic activity: an increase in the excess bond premium reflects a reduction in the effective risk-bearing capacity of the financial sector, with recessionary effects on the economy through a contraction in the supply of credit. 
We include stock prices and credit to the private sector to account for the likely interdependence of uncertainty with the financial side of the economy. The 1-year government bond yield is useful to capture the effects of monetary policy actions on longer-term yields and to overcome the drawbacks of conventional policy rates in the periods characterized by the zero lower bound and nonconventional monetary policy interventions. Gertler and Karadi (2015) use the 1-year yield as the monetary policy indicator as its innovations incorporate the effects of surprises in the current funds rate but also revisions to forward guidance.

Uncertainty indices and the excess bond premium are available at a monthly frequency, so we transform them into quarterly series by averaging their values over the quarter. We estimate the system over the sample 1979-2018. The starting date of the sample depends on the Jurado et al. (2015) uncertainty measures, as they are not available prior to 1979.

Reverting to Figure 1 , the VAR-implied financial (dashed black line) and macroeconomic (continuous red line) U.S. uncertainty shocks are positively correlated (simultaneous coefficient: 0.37). Their simultaneous correlations with the VIX are positive but low (0.19 for macro, 0.17 for financial uncertainty), confirming that uncertainty and volatility in the data track substantially different phenomena. We notice too some substantial differences in the interactions of recession intervals with the level and type of uncertainty. The latter half of the sample shows more frequent and persistent uncertainty shocks, especially of the macro type.

In Figure 2, panel a, we plot the impulse response functions from the U.S. model, estimated using the financial uncertainty composite indicator. The responses show that the uncertainty shock triggers significant recessionary effects, with a GDP trough about 4-5 quarters after the shock; inflation and commodity prices fall too. This evidence points to a steady decline in economic activity, as in Jurado et al. (2015), rather than a volatility overshoot (Bloom, 2009). The response of the excess bond premium and credit point to a contraction too in funding conditions, with a lag profile - notice the swift reaction of the former - that is in line with existing evidence. Interestingly, our estimates capture a significant and substantial downward reaction of stock market valuations and bond yields, fitting a dynamics that is very close to recent theoretical models of the effects of financial shocks (Kiyotaki and Moore 2019). This picture also corroborates the idea that uncertainty shocks engender essentially demand-side contractionary responses (Leduc and Liu 2016).

Figure 2, panel b, shows the impulse responses we extract when the macro uncertainty shock enters the model instead. The reactions of macroeconomic variables indicate a deeper and much 
more persistent downturn following this variety of uncertainty shock. This difference is remarkable also because it confirms that the use of uncertainty indicators based on financial information only is likely to miss important elements of evidence. Overall, the responses highlight a strong transmission of uncertainty shocks throughout the U.S. economy, along lines very similar to those Ludvigson et al. (2019) and other studies gather.

\subsection{EMEs' macroeconomic dynamics}

We now proceed to investigate the effects of U.S. uncertainty on nine major emerging market economies: Brazil, China, Czech Republic, India, Mexico, Russia, South Africa, South Korea and Turkey. For each country, we estimate a VAR model in which the contemporaneous value plus 8 lags of the uncertainty shock enter as exogenous regressors; we then compute the impulse response functions with respect to it. We estimate single-country models, rather than pooled regressions as in the panel perspective often adopted in the literature, because of the need to account for cross-country heterogeneity. In particular, we believe that there are important differences, in time variation and other dynamic structural features, amongst EMEs that a pooled approach would blur. Empirical evidence (see for instance Ahmed et al. 2017; Mehrotra et al. 2019) confirms that the effects of changes in U.S. interest rates critically depend on the extent to which the receiving economy displays macro-financial vulnerabilities. Last, differences in data availability for some countries would yield weakly consistent estimates, an overlooked problem in existing analyses.

In order to capture salient business-cycle and macro-finance features, we build a VAR specification extended to key asset values. In particular, we include the following dependent variables at quarterly frequency: real GDP, the GDP deflator, the ratios over GDP of credit to the private sector and of capital inflows, real house prices and real stock prices, a short-term interest rate and the real effective exchange rate. We include house prices and stock prices to evaluate the effects of changes of U.S. uncertainty shocks on local assets and to account for their role in the transmission mechanism of the shocks. As for the short-term rate, we aim at capturing the behaviour of the monetary authority; for this reason, we choose an interest rate tightly correlated with the policy rate (see Table 1 for its definition). Commodity prices are a relevant source of inflation and business fluctuations for emerging economies, therefore we also include the contemporaneous value of the CRB index of commodity prices as an exogenous regressor. Real GDP, the GDP deflator, real house prices, real stock prices, the real effective exchange rate and commodity prices all enter in log 
levels, while the other variables in plain levels. Some of the variables are not available for all the countries in our sample, so that the VAR models exclude one or two of the variables listed above. The estimation sample starts in $\mathrm{Q}_{2} 1982$ and ends in $\mathrm{Q}_{4}$ 2018. For some countries, we use shorter samples due to data availability. Table 1 summarizes the dataset information. We consider 5 lags of the endogenous variables.

As for the U.S., we estimate the models for the EMEs by relying on Bayesian inference. For the priors, we follow a setup similar to the previous step, i.e. we use the Normal-Inverse-Wishart prior and combine it with the dummy-initial-observation and sum-of-coefficients priors. In this case, hyperparameters are fixed so that the models are comparable across countries. More in details, we specify a Minnesota prior for the coefficients with overall tightness of 0.01 . The tightness of the dummy-initial-observation and the sum-of-coefficients priors are 0.01 and 0.1 , respectively. These two priors account for unit root and cointegration; our setup favours cointegration over unit roots, which we see as a reasonable assumption. ${ }^{5}$

We generate 5000 draws from the posterior distributions of the parameters; we discard the first 2000 draws while we retain the last 3000 for inference. The results are shown in Figures from 3 to 10; we organize the plots by variable so as to simplify comparisons amongst countries.

We complement our analysis by considering the contribution of each structural shock to the historical dynamics of the data series. This historical decomposition is displayed in Figures from 11 to 19. The charts show the contribution of each structural shock to the actual values of the variables. For this reason, the output depends on the variables included in the model and on the identification strategy. Here, our ultimate goal is to assess the contribution of the uncertainty shock, which is exogenous, so that for the endogenous shocks we apply a Cholesky decomposition and order the variables as listed at the beginning of this section. Further, we compute the historical decomposition for every draw of the posterior distribution, and show the median result.

Figures 3-11 show the impulse response functions to financial (blue areas) and macroeconomic (red lines) uncertainty shocks for the nine countries in our sample.

Starting with the response of GDP (Figure 3), we find that a U.S. financial uncertainty shock has a significant and strong contractionary impact in some of the countries, notably Russia, India, Turkey and Czech Republic, whilst for the others the effect is weaker or not significant outright. For China it is small but significant. On the other hand, only in Russia, Turkey and South Africa the macro shock tends to trigger a significant decline in output. Where the contraction does take place, GDP

${ }^{5} \mathrm{~A}$ Johansen cointegration test confirms that the systems are characterized by at least one cointegrating relationships. 
hits a trough approximately 6-8 quarters after the shock. The response of inflation (Figure 4), however, is muted: even for the countries experiencing the deepest GDP falls, inflation does not follow suit. This dynamics is not surprising, as other complex drivers and factors outside our relatively parsimonious model likely drive the reaction of prices in these economies.. Indeed, there is ample evidence that the very open nature of EMEs implies a low sensitivity of inflation to domestic output developments, other things being equal (see Obstfeld 2020).

The response of the credit/GDP ratio too (Figure 6) differs across countries. In Brazil, China and South Korea credit significantly rises, on average about 5-7 quarters after the shock. Credit expansions in these countries are likely to be an endogenous reaction of monetary policy to the worsening of international funding conditions. Indeed, for most of the countries, capital inflows (Figure 5) tend to decline and the real exchange rate depreciates (Figure 8), as expected following a recessionary impulse. This evidence is consistent with a flight-to-safety effect. Monetary policy interventions apparently tend to be of a quantitative nature, as the interest rate (Figure 7) does not show a significant response, probably because of efforts to limit appreciation pressures on the exchange rate. In addition, exchange-rate variations could somewhat blur the response of market interest rates to aggregate-demand shocks.

Based on evidence gathered in, amongst others, Miranda-Agrippino and Rey (2020), the Global Financial Cycle hypothesis claims that a single common factor causes substantial international comovement in asset prices. Turning to our estimates of the response of stock prices (Figure 9), we find a generalized tendency of equity values to fall following the U.S. uncertainty shock. This result is particularly valuable as we derived it at the quarterly, business-cycle frequency of our analysis. We detect a stronger response (peaking at around $-5 \% /-10 \%$ ) with the financial variety of the shock. This effect is much less evident in the behaviour of house prices (Figure 10): only in South Africa the decline is statistically significant. This lack of significant reaction might be due to the more sluggish dynamics and complex determinants of property values.

Overall, many of the responses of EME countries appear stronger than for the U.S. economy. As regards output and prices, our results are generally at odds with those of Bhattarai et al. (2019), as they find a steady fall in these variables. On the other hand, we also find non-significant responses in output and prices of Latin American countries (Brazil and Mexico in our sample). Our results for the exchange rate, stock prices and capital flows are consistent with Bhattarai et al. (2019). However, our framework allows us to better characterise cross-country heterogeneity in the responses, which indeed turns out to be substantial. 
Historical decomposition of data into shocks further assists us in understanding the role of uncertainty shocks. Specifically, each chart in Figures 11-19 plots the portion in the variable's historical dynamics - more precisely, of the deviation from its initial or steady-state level - that is due to each of the structural disturbances and to the U.S. uncertainty shock. As before, we show estimates obtained by inserting alternatively the financial and macroeconomic variety of the U.S.originated uncertainty disturbance. The dynamics we uncover are quite rich in that they allow to clarify the key role of uncertainty during notable macroeconomic events of each country. Besides, we summarize in Table 2 the main regularities: we list the variables for which U.S. uncertainty triggers a rise $(+)$ or a fall $(-)$, and type in bold the strongest contributions.

Estimates confirm that both types of U.S. uncertainty have had substantial effects on the variables of the system. The largest proportional contributions - either positive or negative - of uncertainty shocks have been to the dynamics of capital flows, GDP, credit, stock prices and the short interest rate. Macro uncertainty accounts for slightly smaller contributions, for in some countries it tends to elicit responses of a different sign. Capital flows appear as particularly sensitive to uncertainty shocks. As for GDP, U.S. uncertainty seem to contribute significantly to output fluctuations in all economies bar China, the largest one. Interestingly, it tends to prompt systematic contractions in South Korea, perhaps because it also engender an increase in the short rate, and an expansionary effect for Turkey and South Africa, where credit tends to increase. In all remaining economies, though substantial, its impact is more difficult to classify. Last, the decomposition points to U.S. financial uncertainty shocks accounting for a negative impact on stock market values in Brazil, Czech Republic and South Africa; a positive one for India, Mexico, Russia, South Africa, South Korea. This evidence confirms the international propagation of adverse uncertainty shocks through international stock indices.

\section{Conclusions}

In this paper, we explore empirically the transmission of U.S. financial and macroeconomic uncertainty to emerging market economies (EMEs). With the help of two varieties of uncertainty shocks derived in the context of a Bayesian VAR on U.S. quarterly data, we estimate VAR models for nine major Emerging-Market Economies. The differentiated dynamics we uncover shed new light on the nexus between U.S. funding conditions, their interplay with uncertainty, and their joint propagation to key macroeconomic and asset values worldwide. 
Our estimates for the U.S. show that uncertainty shocks have significant adverse effects on the level of economic activity. Both real and financial variables follow a clear recessionary path, with GDP undergoing a particularly strong and persistent downturn when we employ the macroeconomic definition of uncertainty in our VAR.

However, we detect significant cross-country differences in the responses of EMEs' business cycles to U.S uncertainty shocks. While in some countries heightened uncertainty does trigger significant output contractions, others exhibit responses that are essentially muted. The same mixed picture emerges for inflation, interest rates, credit aggregates and capital flows: some economies seem more tightly connected with U.S. monetary and uncertainty developments than others. We thus confirm that differences in institutional arrangements or in macro-financial vulnerabilities may account for critical heterogeneity in the sensitivity of local business cycles to international developments. On the other hand, our results for stock prices (not those for property values) corroborate the Global Financial Cycle hypothesis: stock prices display a generalized tendency to fall following the U.S. uncertainty shock, especially of the financial type, as expected.

As regards future extensions, we plan to improve upon the identification of uncertainty shocks by exploiting narrative and sign restriction as in Redl $(2020)^{6}$ and, possibly, adopt some magnitude restriction in the spirit of Ludvigson et al. (2019). This would allow us to allow for contemporaneous feedbacks between uncertainty and other macroeconomic variables.

${ }^{6}$ Antolin-Diaz and Rubio-Ramirez (2018) develop narrative restrictions. 
Figure 1, US: VIX and implied macro and financial uncertainty shocks.

Estimated uncertainty shocks, $1980 \mathrm{O}_{2}-201804$. The lines represent the VIX (rescaled and demeaned, blue line) and the uncertainty shock, derived from estimation of the VAR model for the US, alternatively using the macroeconomic (continuous red line) and the financial (dashed black line) indicators as computed by Jurado et al. (2015). The shaded bars denote NBER-dated recessions of the US economy.

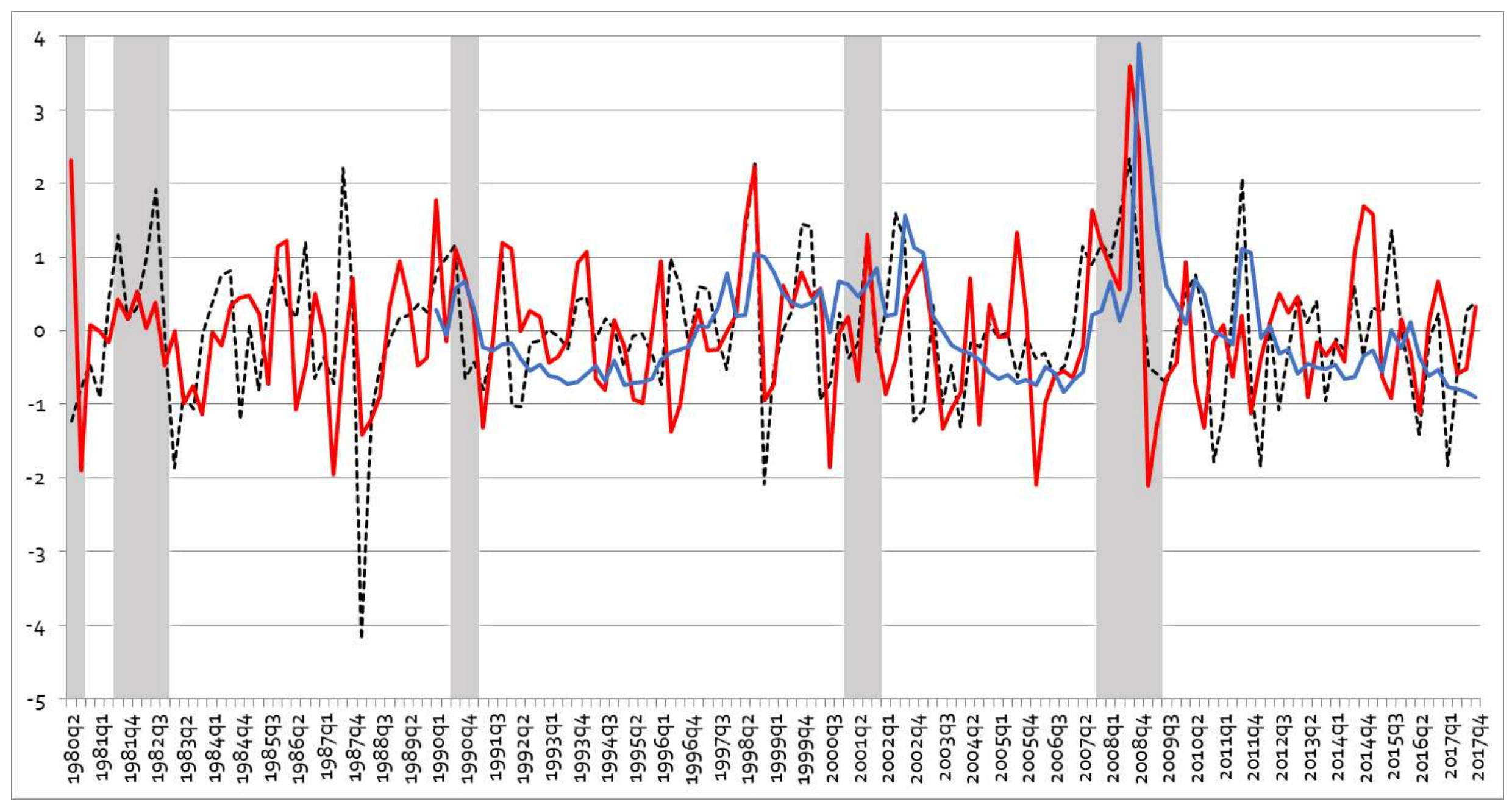


Figure 2: US

Panel a: Model with financial uncertainty
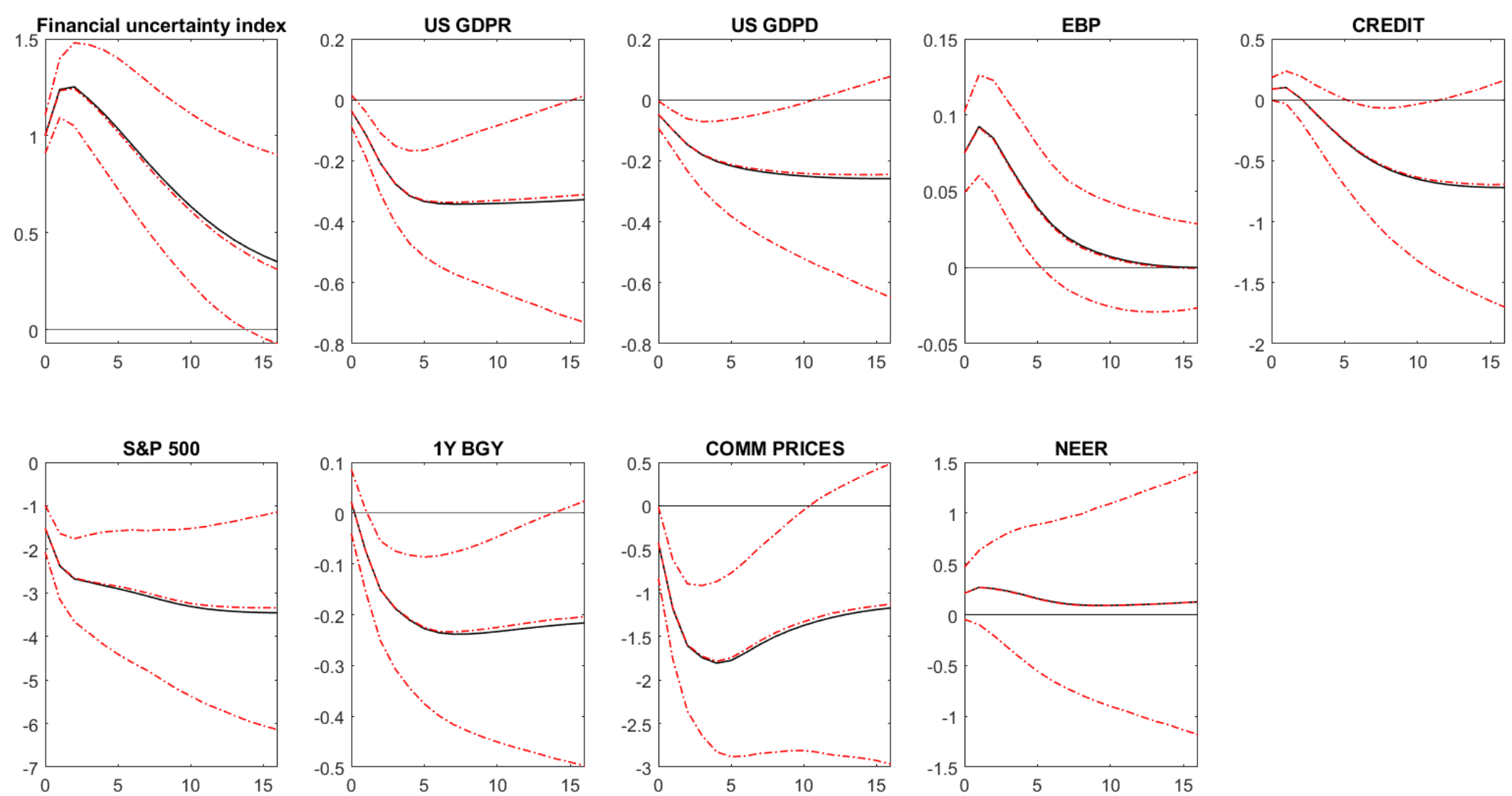


\section{Figure 2: US}

Panel b: Model with macroeconomic uncertainty
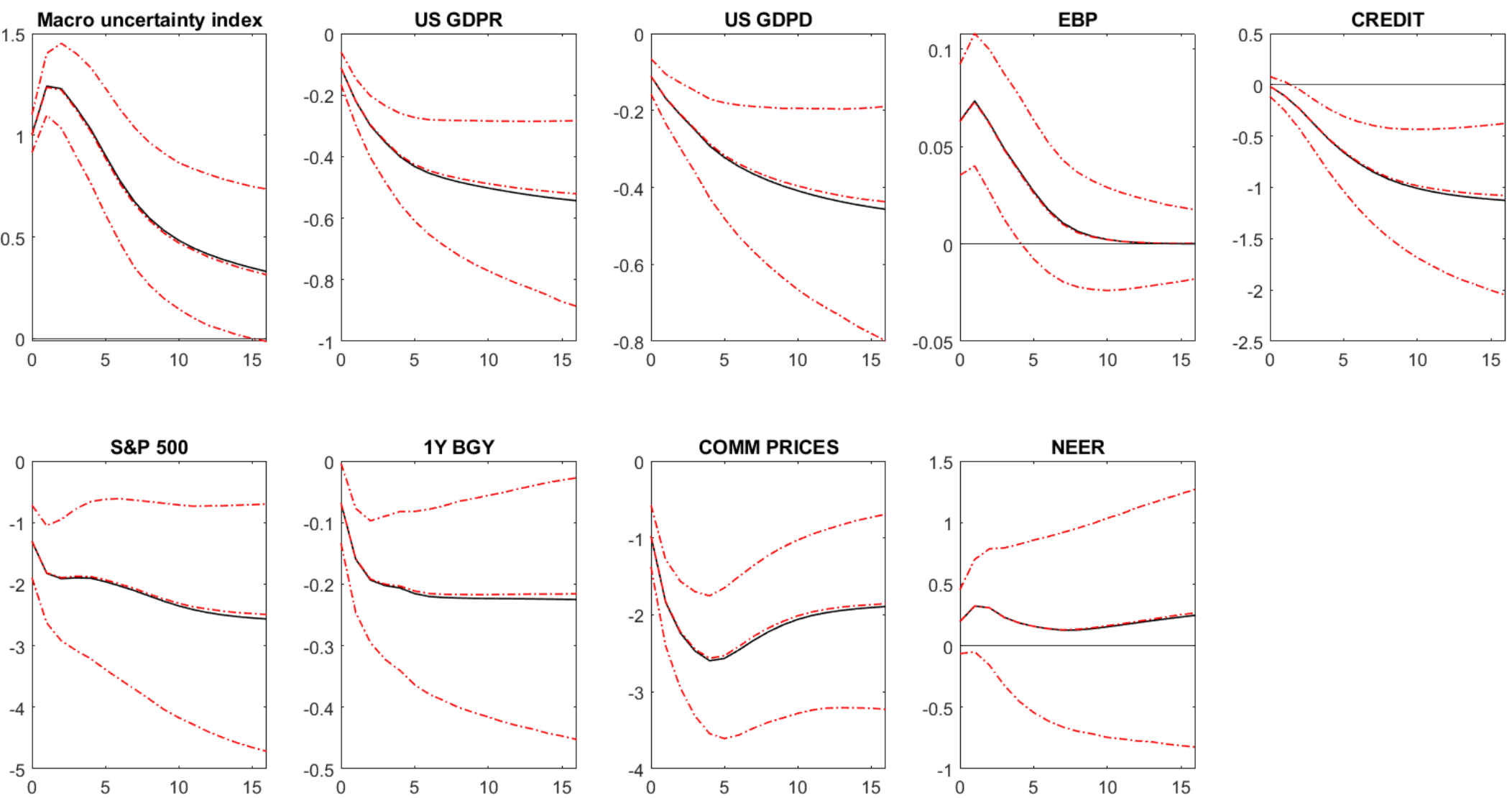
Figure 3: Real GDP

IRFs to financial (blue) and macroeconomic (red) uncertainty shock
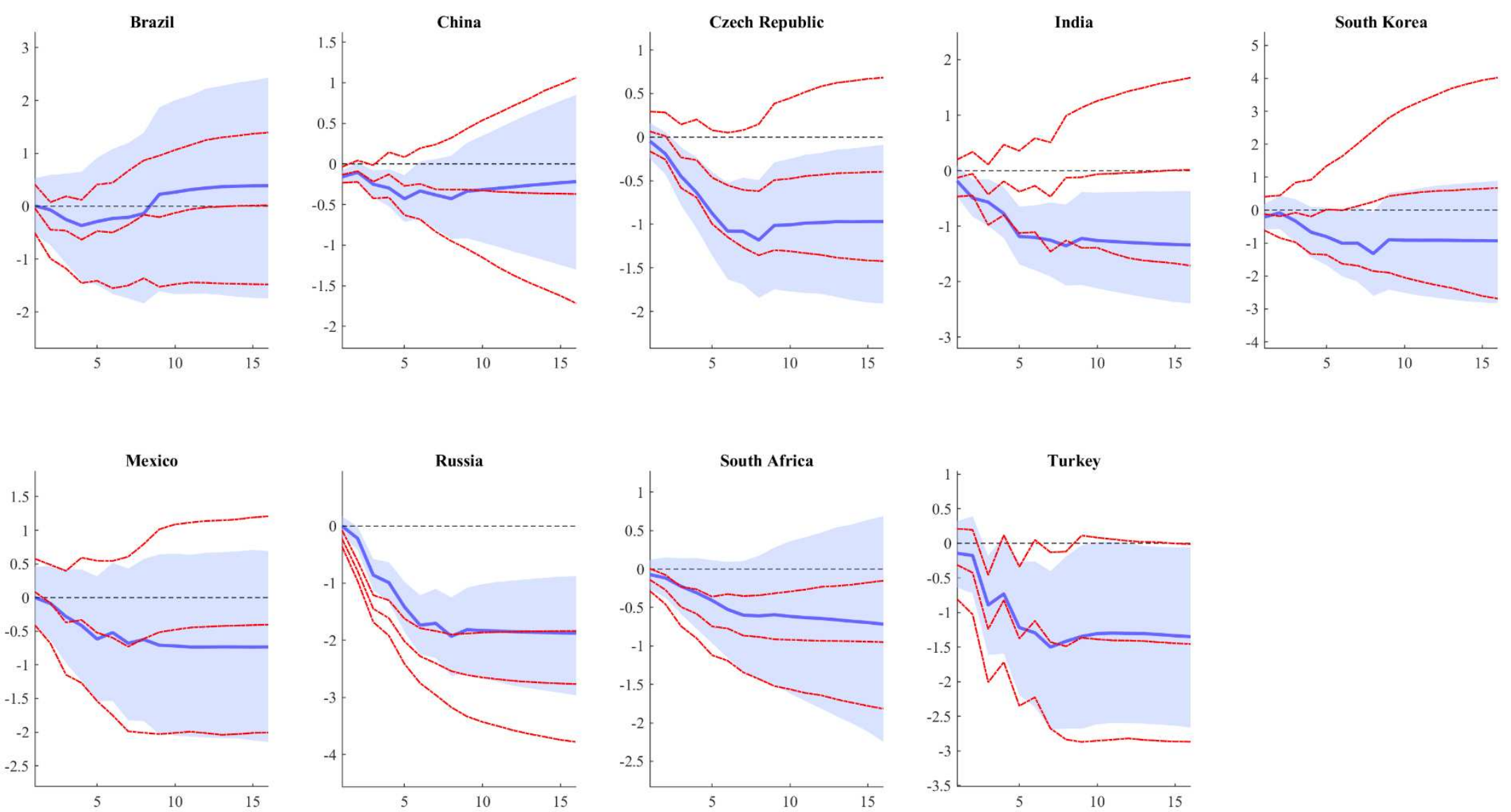
Figure 4: GDP deflator

IRFs to financial (blue) and macroeconomic (red) uncertainty shock
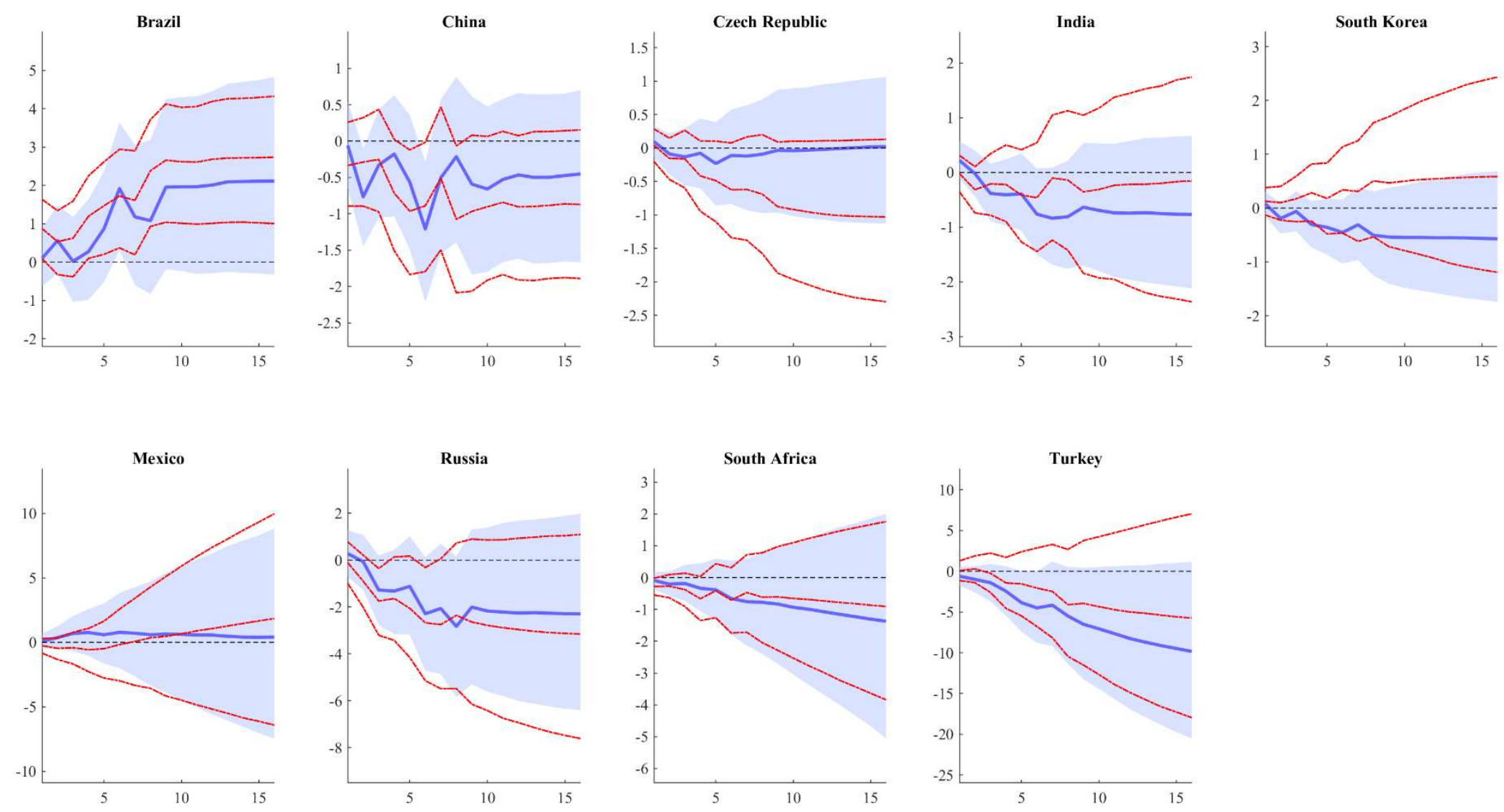
Figure 5: Capital inflows as a ratio of GDP

IRFs to financial (blue) and macroeconomic (red) uncertainty shock
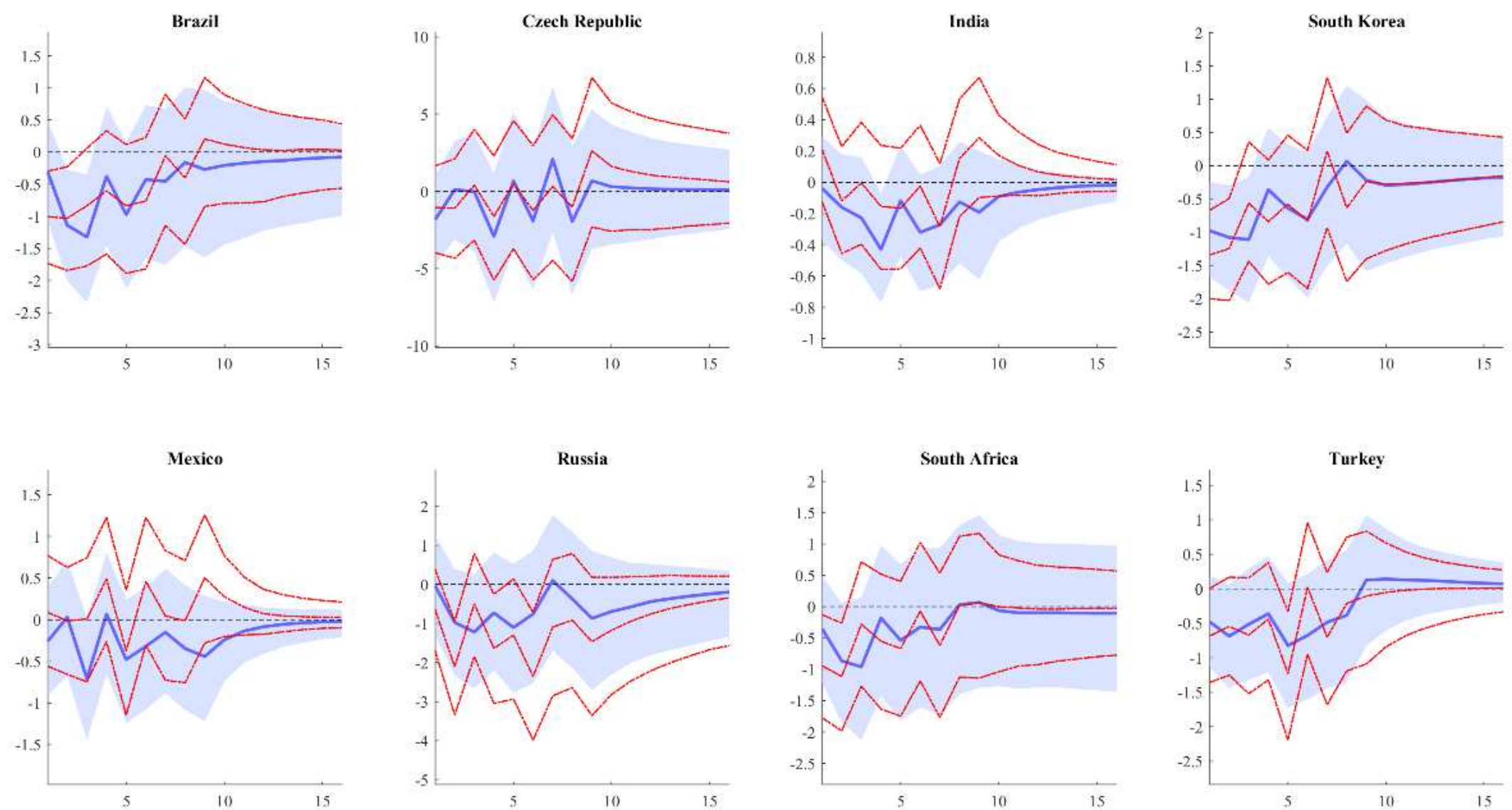
Figure 6: Credit to private sector as a ratio of GDP

IRFs to financial (blue) and macroeconomic (red) uncertainty shock
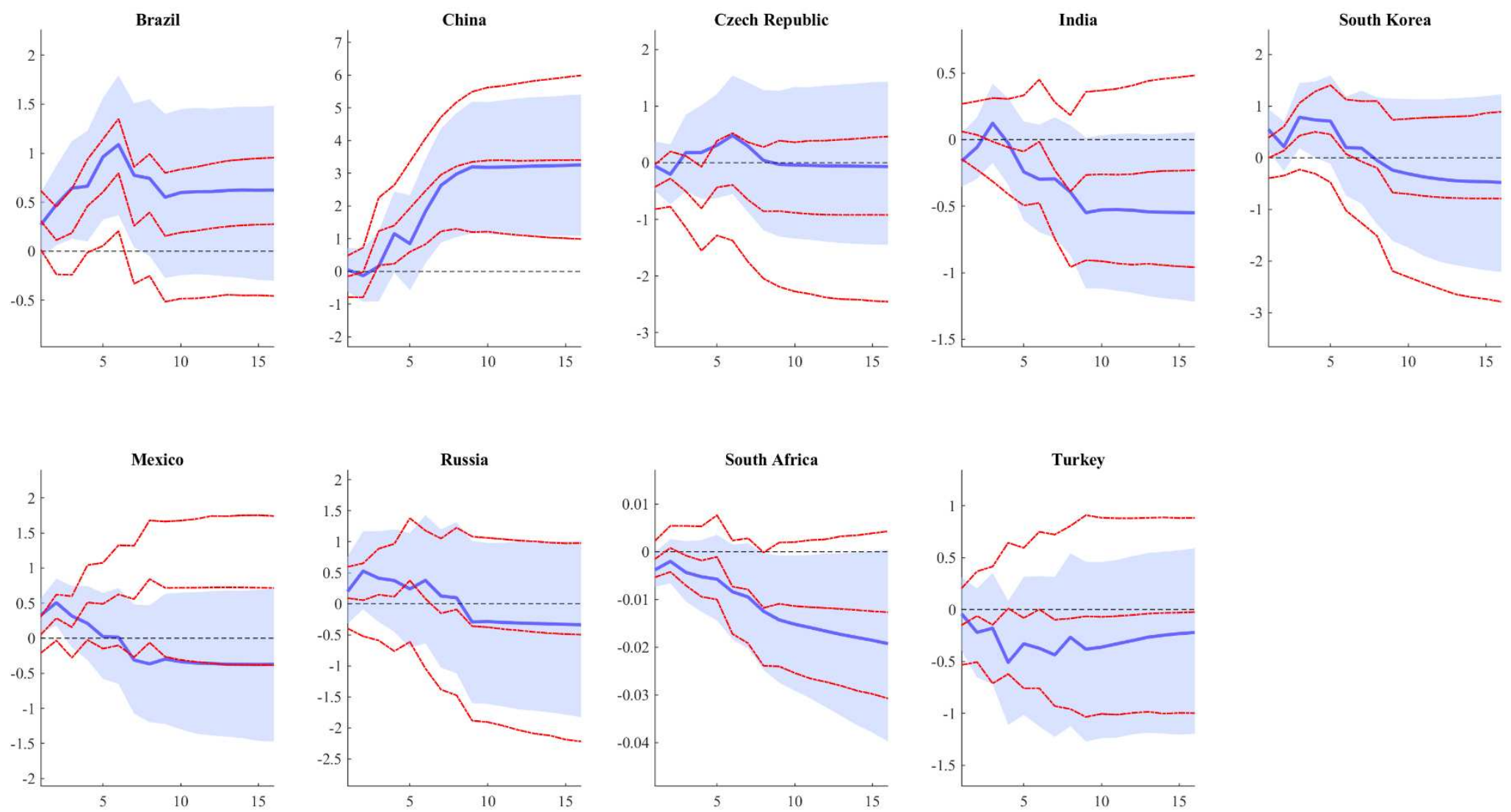
Figure 7: Short-term rate

IRFs to financial (blue) and macroeconomic (red) uncertainty shock
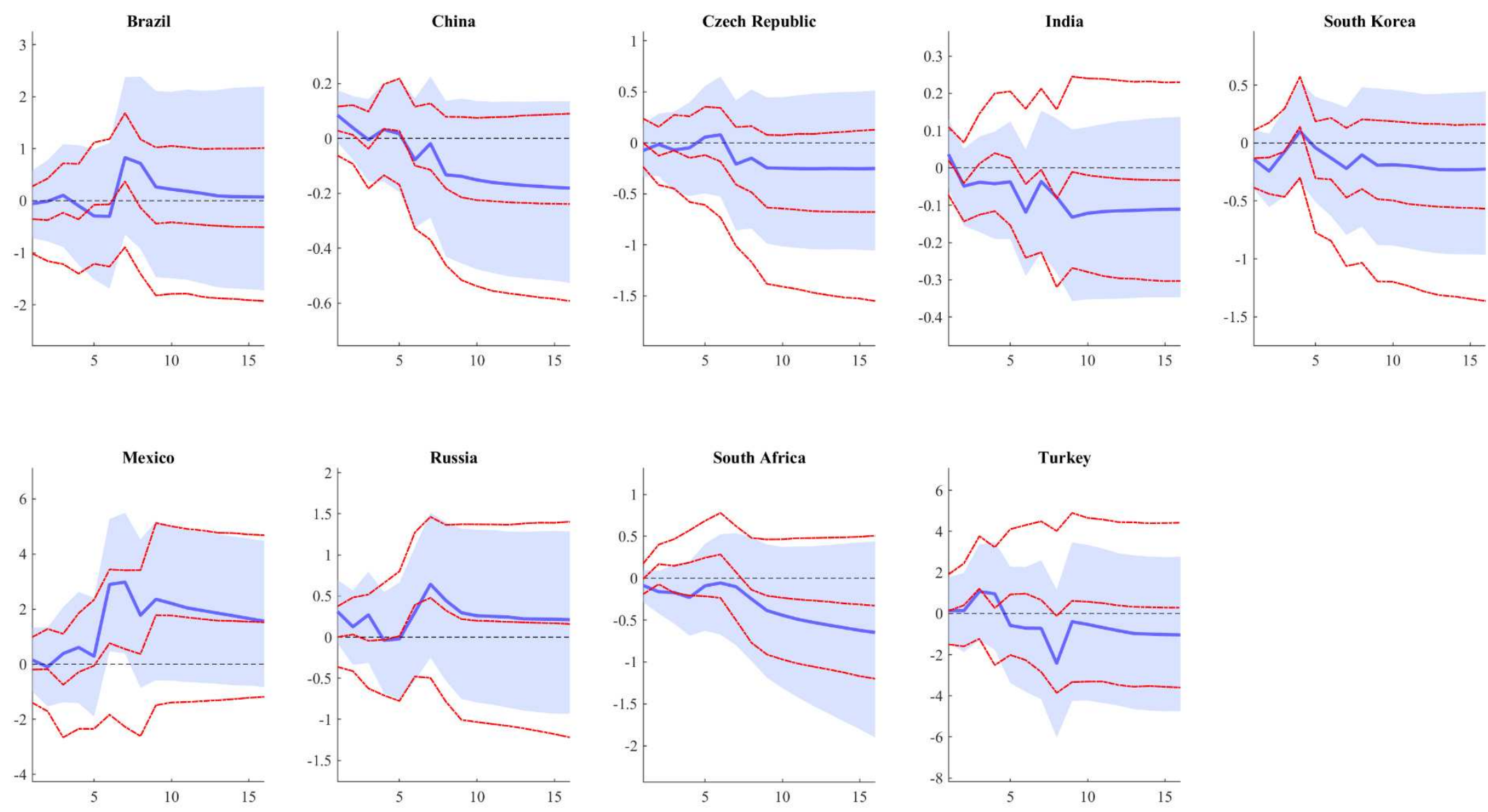
Figure 8: Real effective exchange rate

IRFs to financial (blue) and macroeconomic (red) uncertainty shock
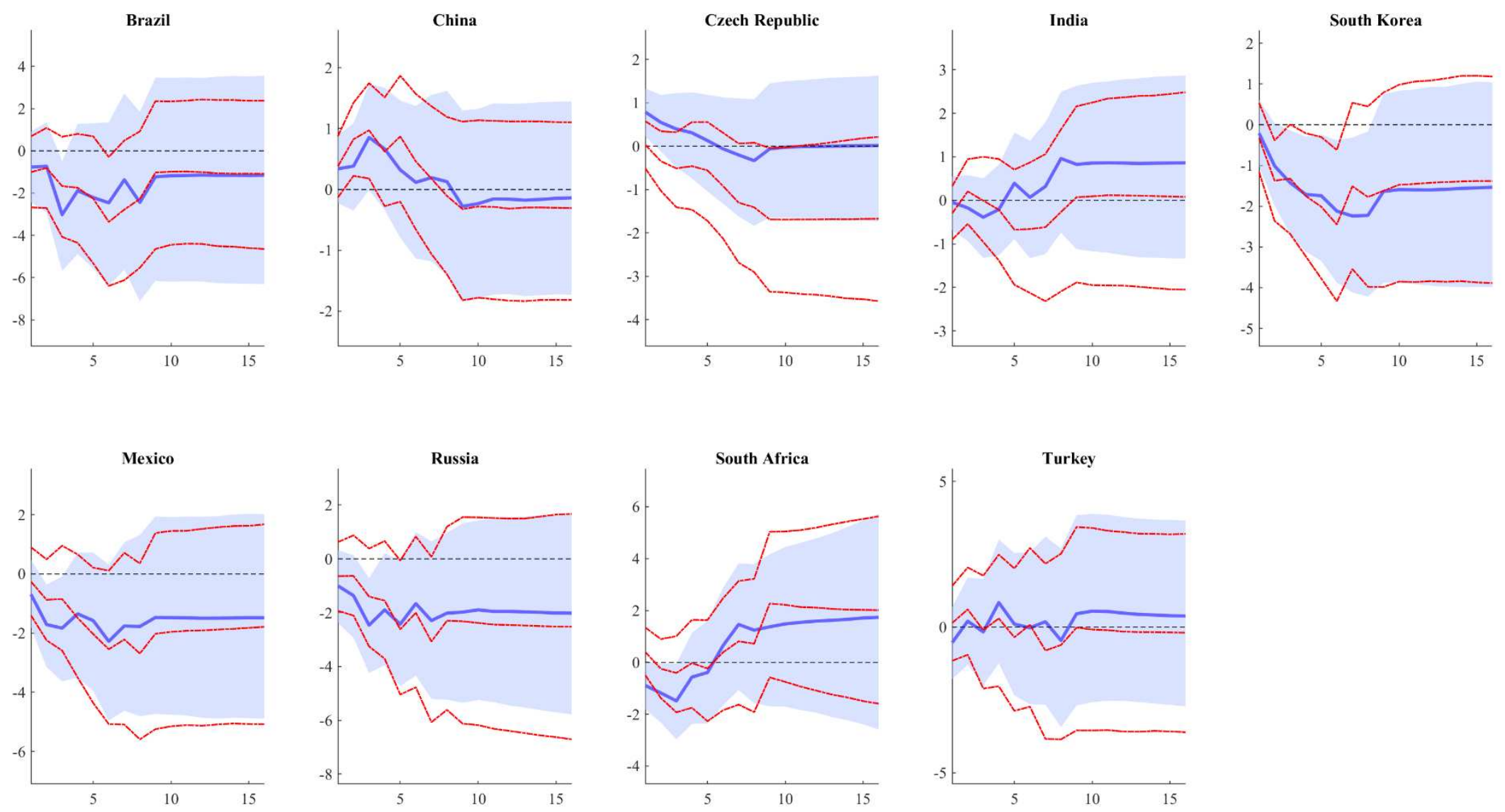
Figure 9: Stock prices

IRFs to financial (blue) and macroeconomic (red) uncertainty shock
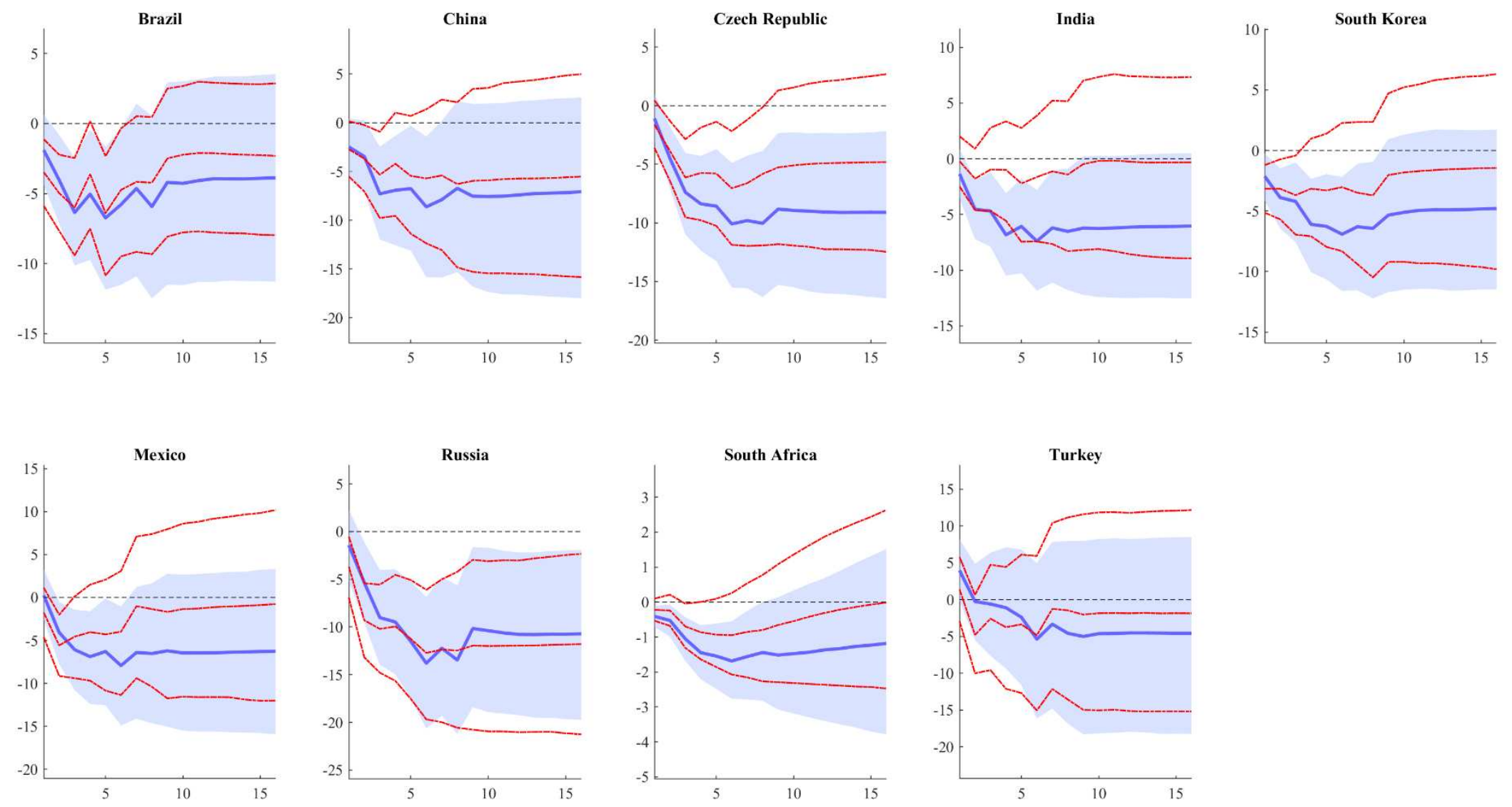
Figure 10: House prices

IRFs to financial (blue) and macroeconomic (red) uncertainty shock
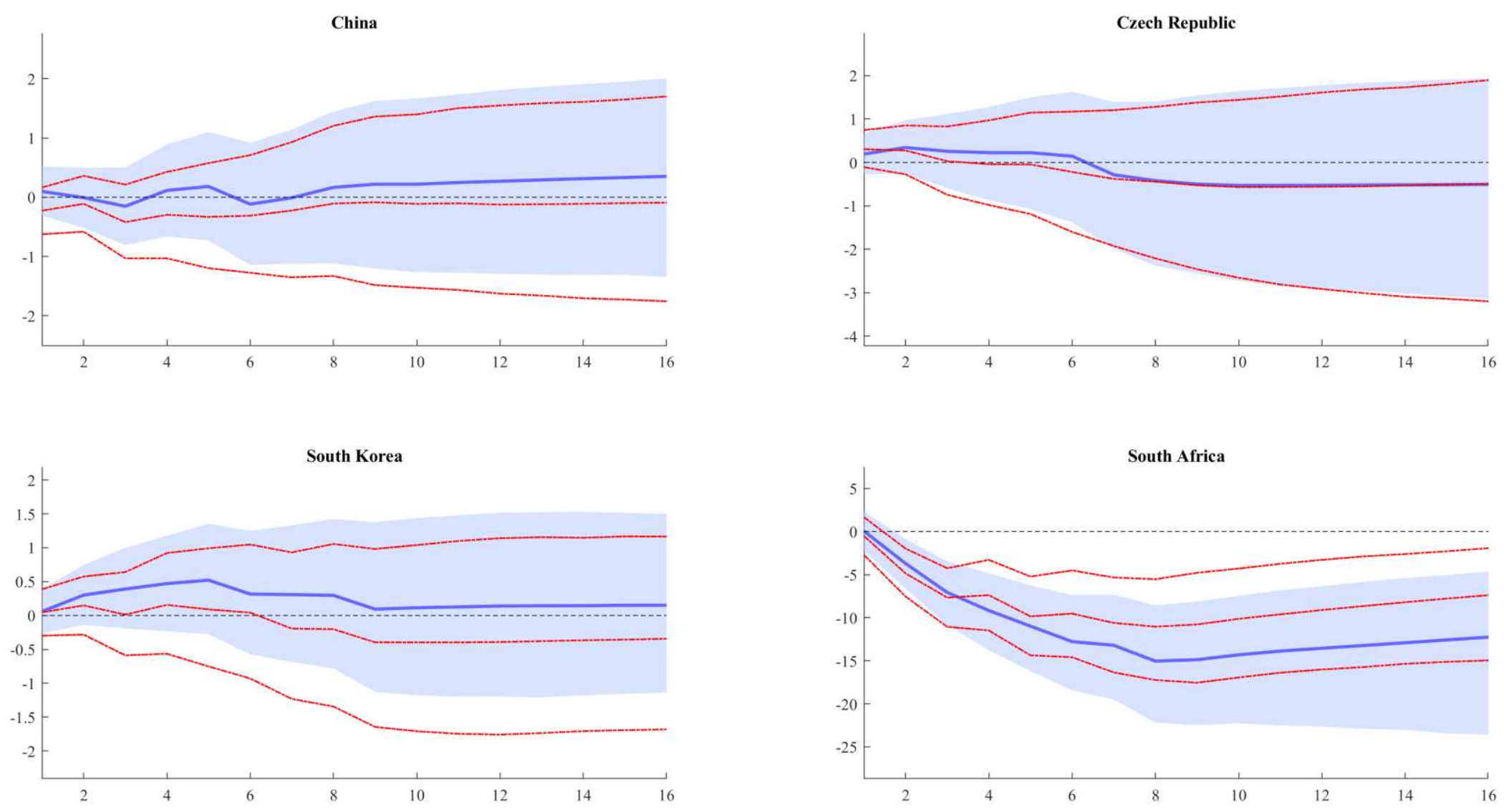
Figure 11: Historical decomposition for Brazil

a) Financial uncertainty shock
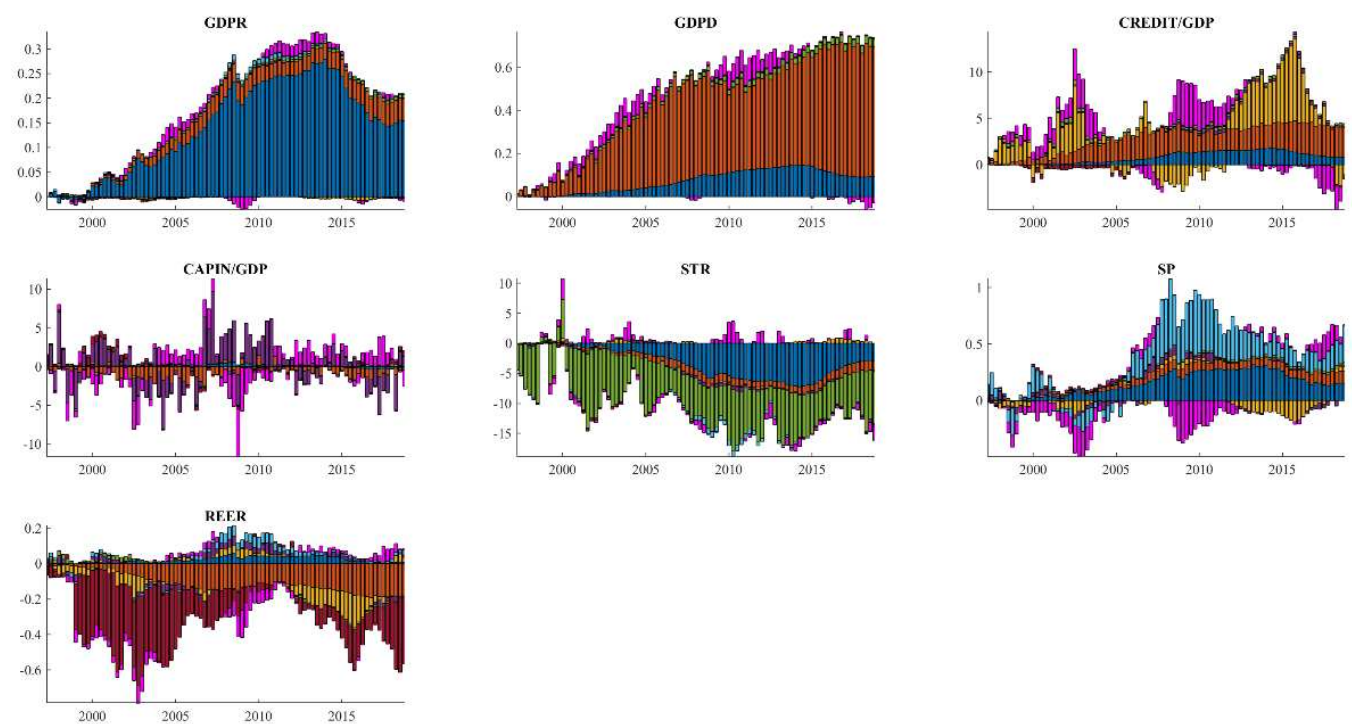

b) Macroeconomic uncertainty shock
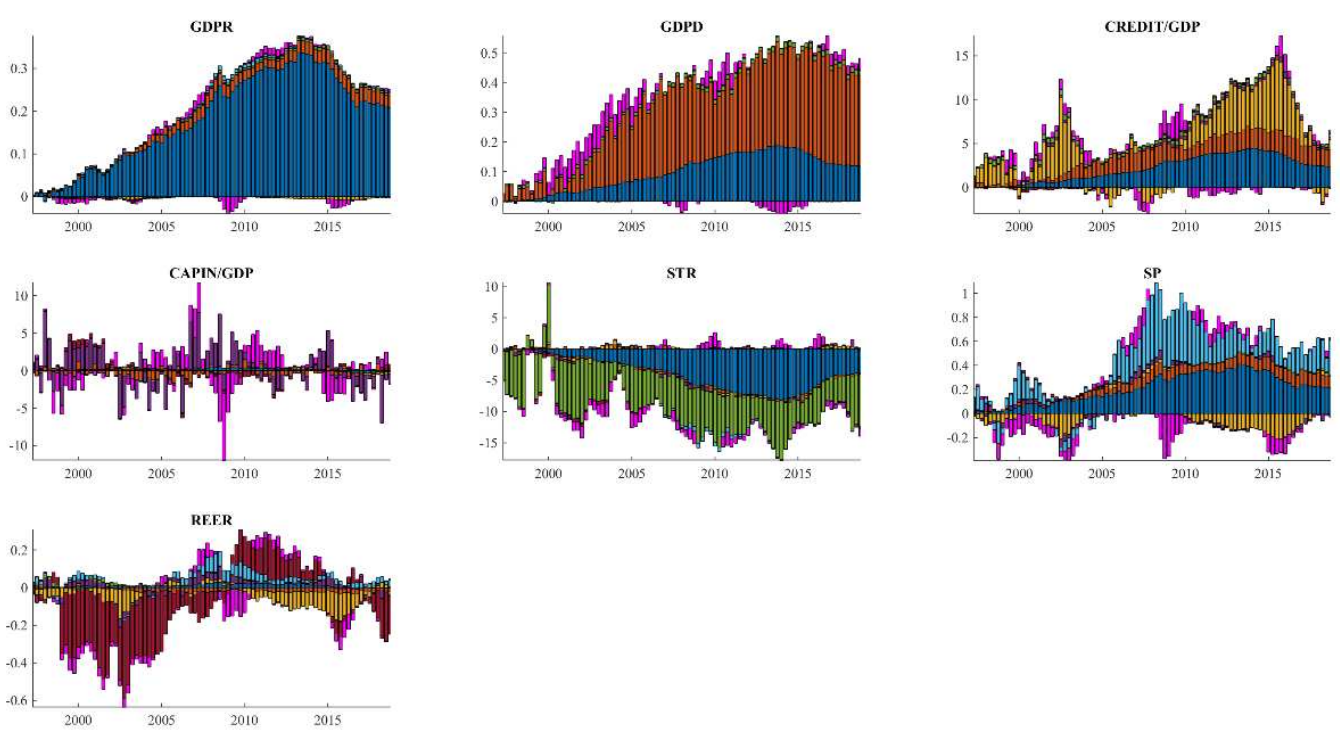

Legend: blue - GDPR, orange - GDPD, yellow - credit/GDP, purple - capital inflows/GDP, green - short term rate, light blue - stock prices, red - REER, pink - uncertainty. 
Figure 12: Historical decomposition for China

a) Financial uncertainty shock
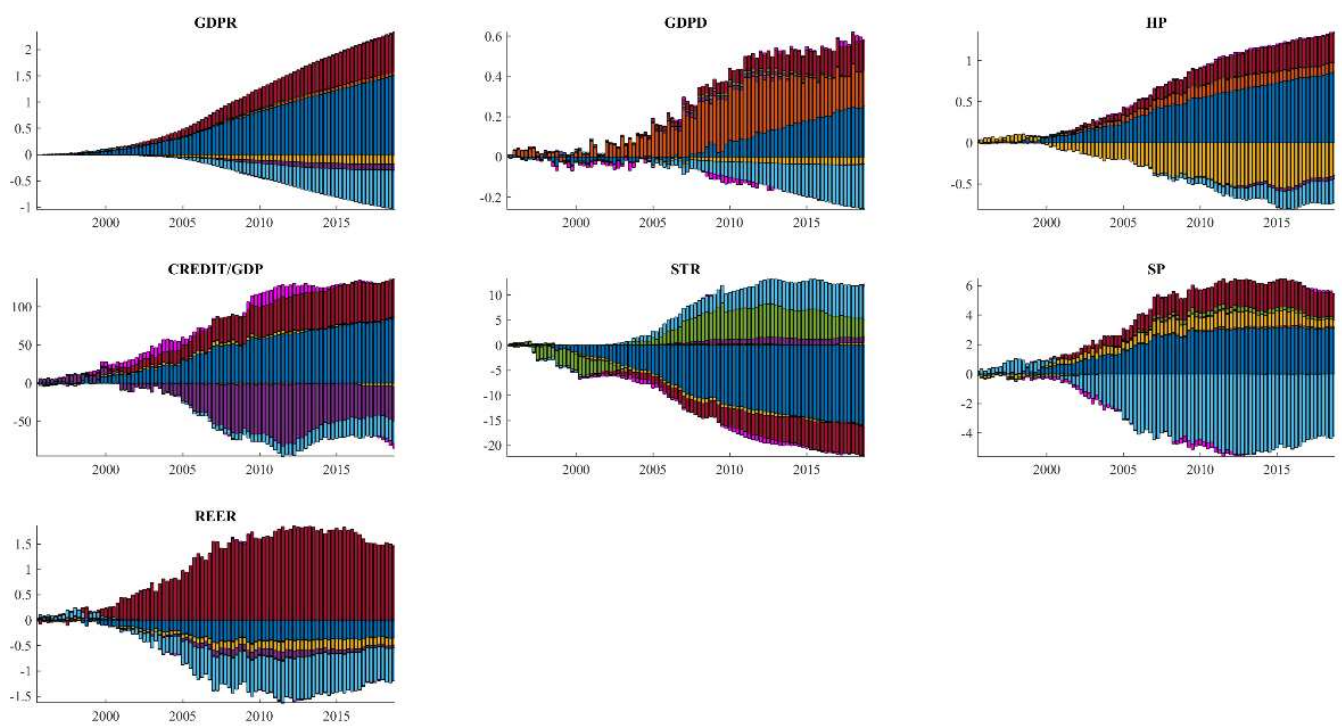

b) Macroeconomic uncertainty shock
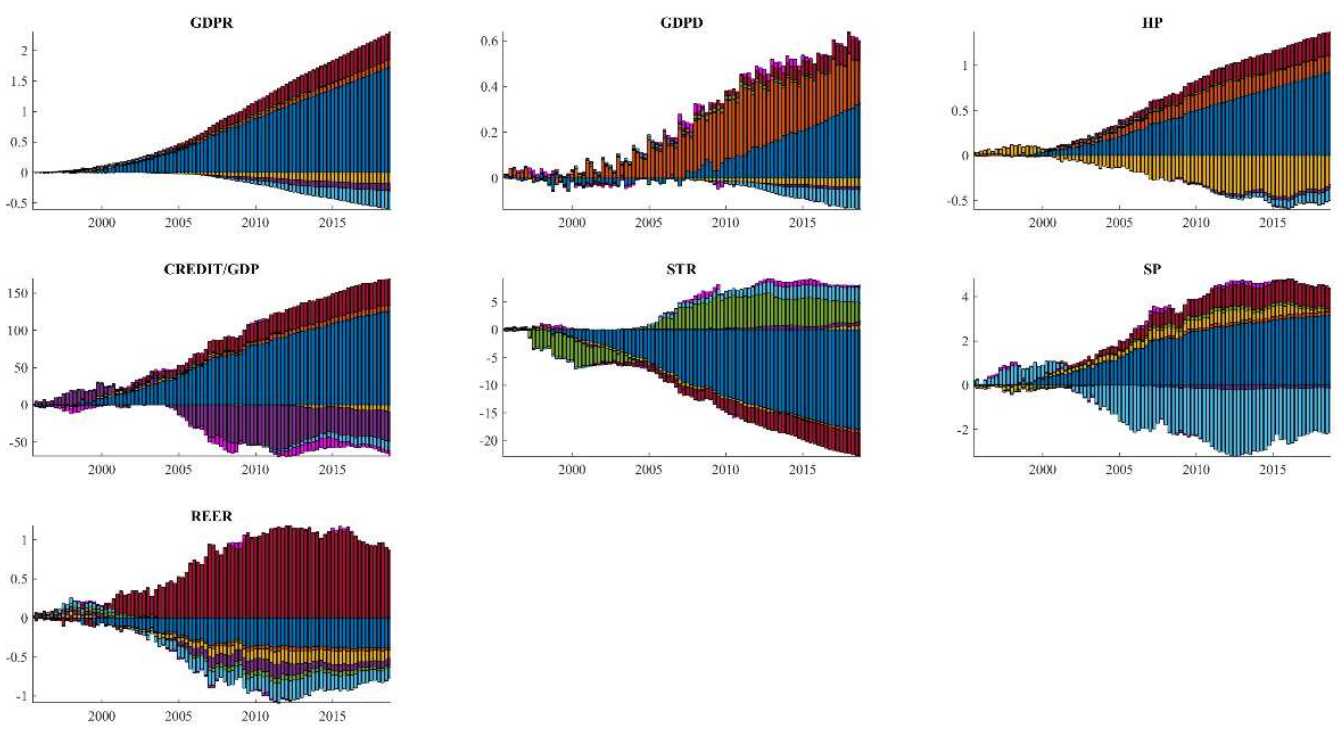

Legend: blue - GDPR, orange - GDPD, yellow - house prices, purple - credit/GDP, green - short term rate, light blue - stock prices, red - REER, pink - uncertainty. 
Figure 13: Historical decomposition for Czech Republic

a) Financial uncertainty shock
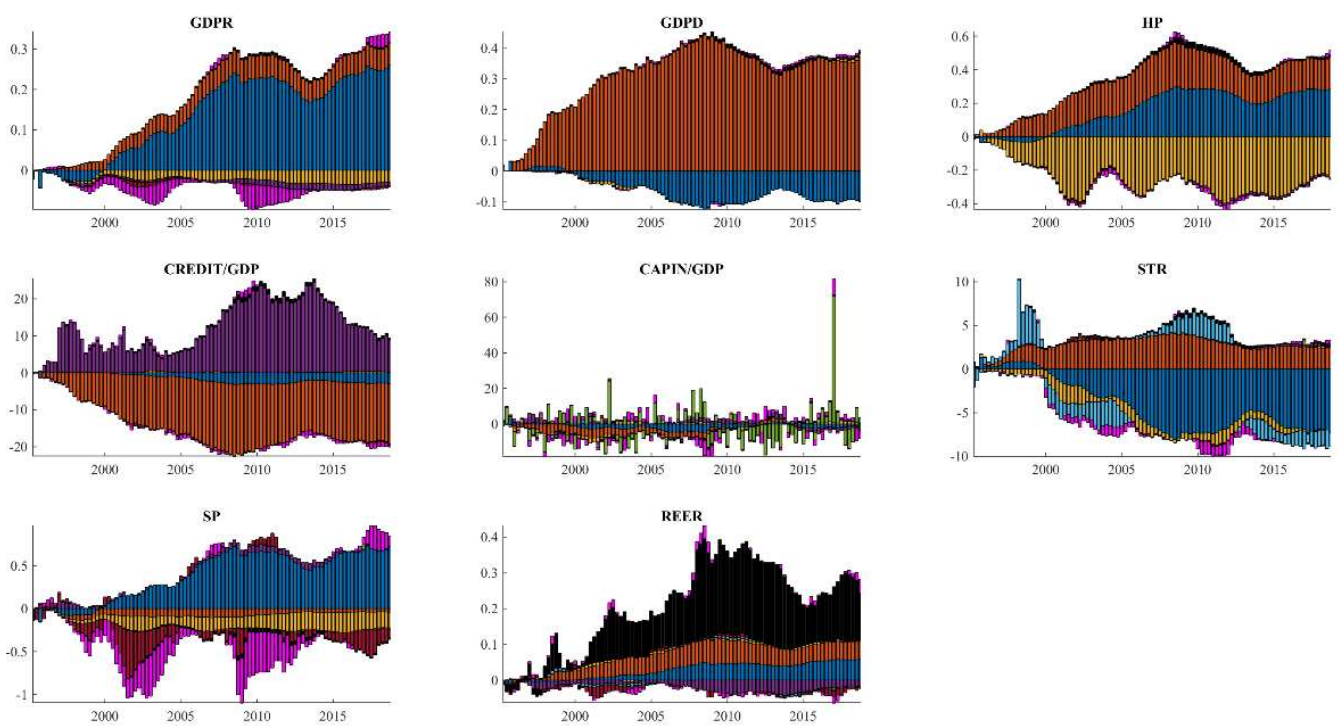

b) Macroeconomic uncertainty shock
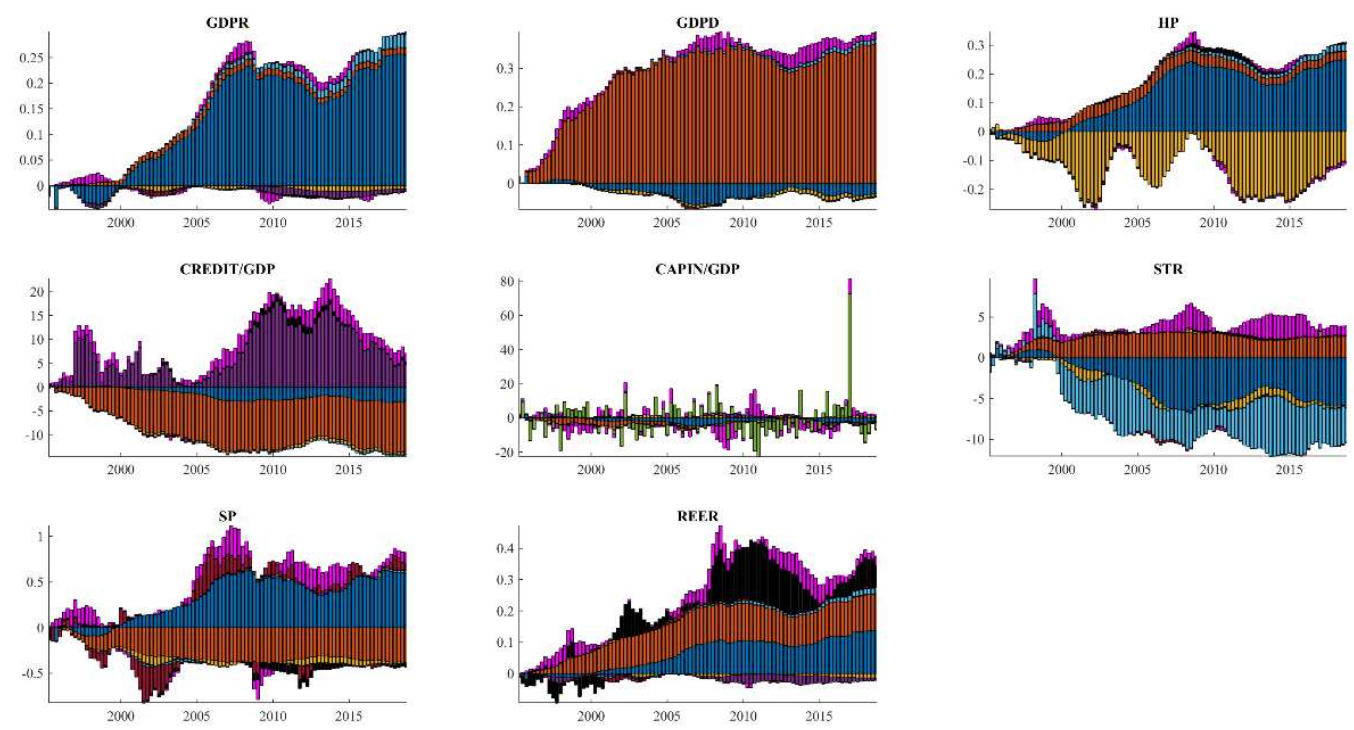

Legend: blue - GDPR, orange - GDPD, yellow - house prices, purple - credit/GDP, green - capital inflows/GDP, light blue - short term rate, red - stock prices, black - REER, pink - uncertainty. 
Figure 13: Historical decomposition for India

a) Financial uncertainty shock
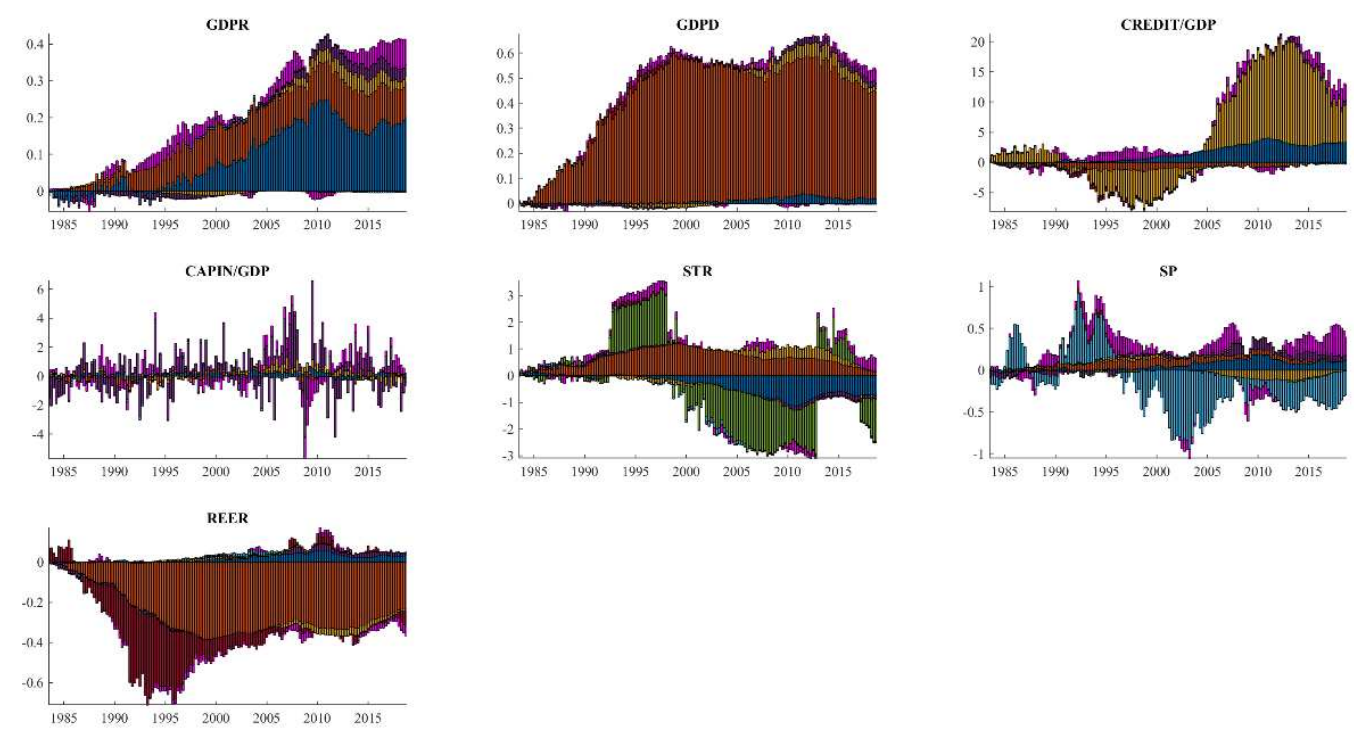

b) Macroeconomic uncertainty shock
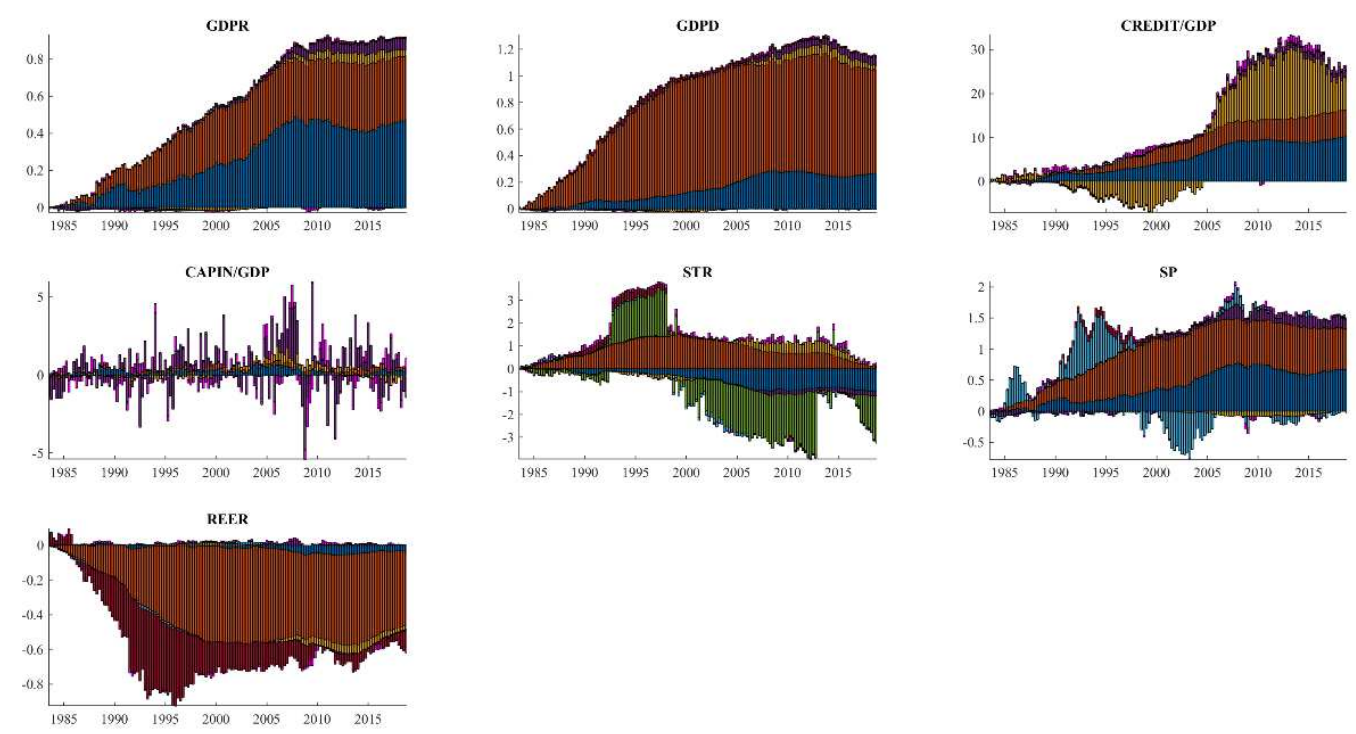

Legend: blue - GDPR, orange - GDPD, yellow - credit/GDP, purple - capital inflows/GDP, green - short term rate, light blue - stock prices, red - REER, pink - uncertainty. 
Figure 15: Historical decomposition for South Korea

a) Financial uncertainty shock
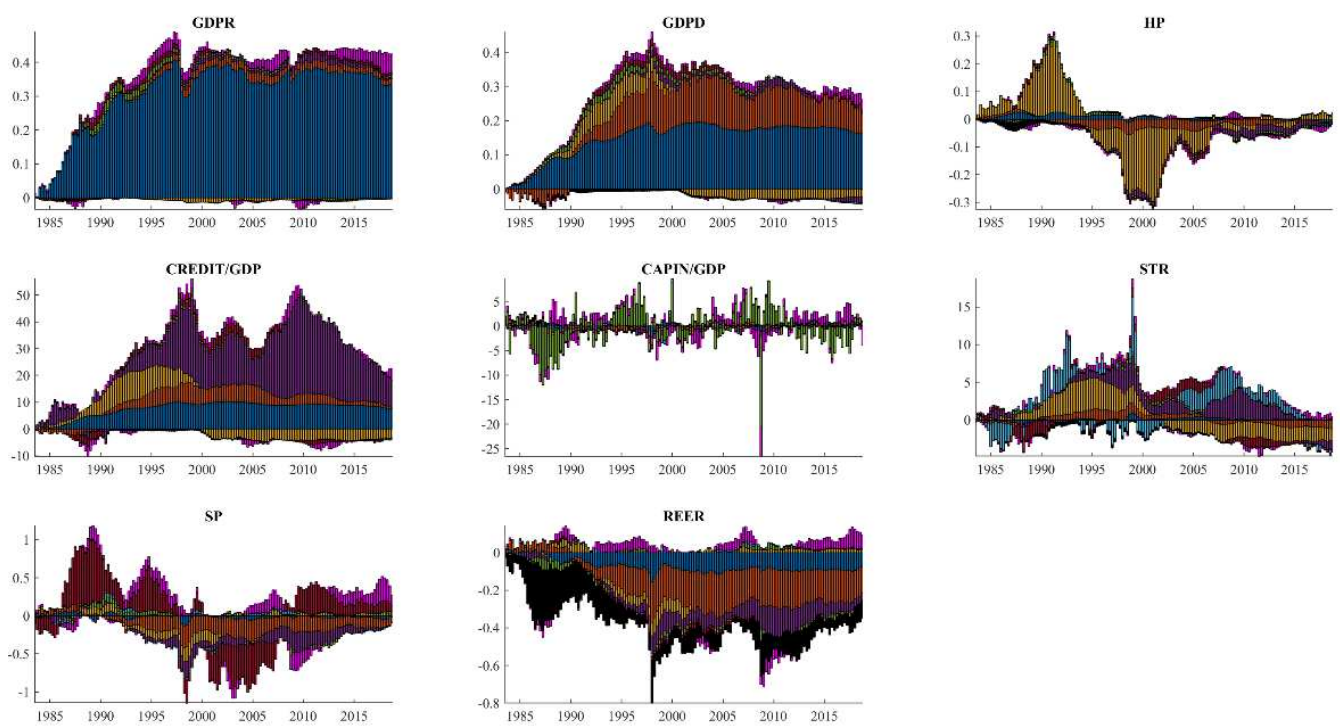

b) Macroeconomic uncertainty shock
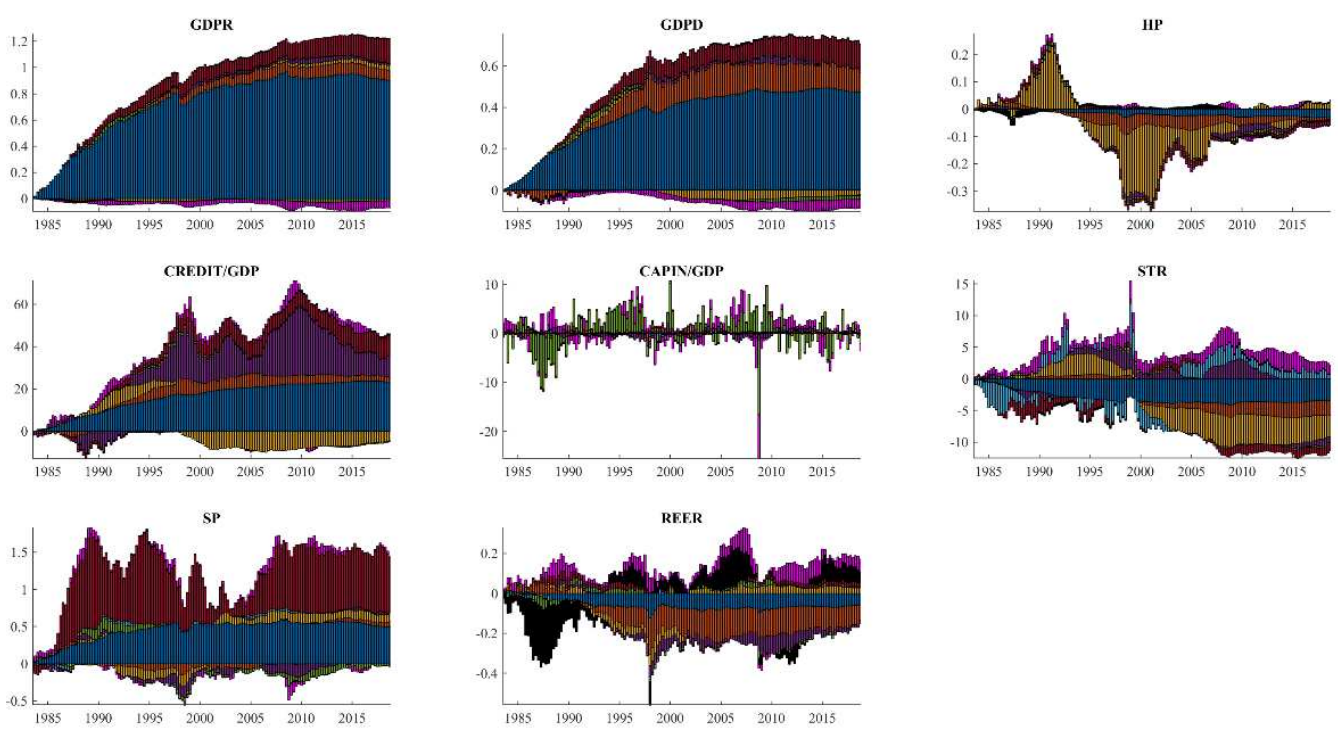

Legend: blue - GDPR, orange - GDPD, yellow - house prices, purple - credit/GDP, green - capital inflows/GDP, light blue - short term rate, red - stock prices, black - REER, pink - uncertainty. 
Figure 16: Historical decomposition for Mexico

c) Financial uncertainty shock
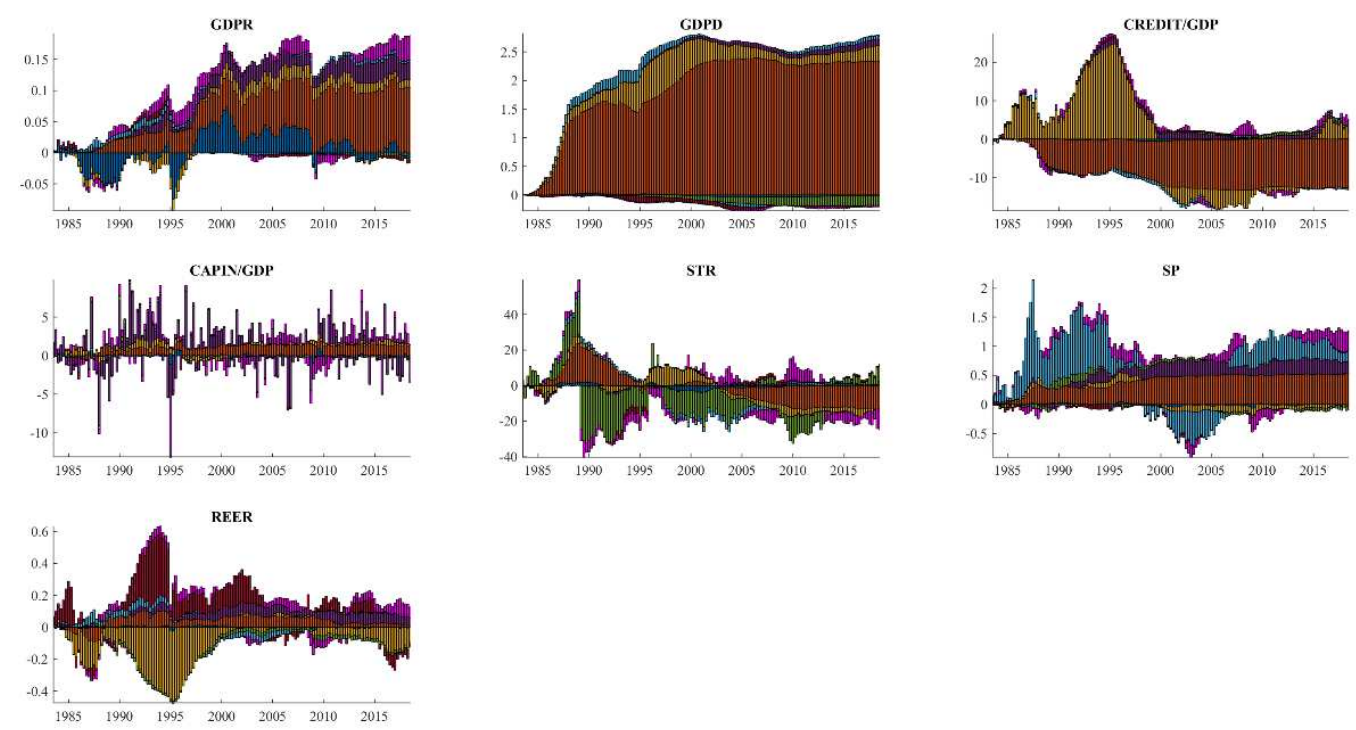

d) Macroeconomic uncertainty shock
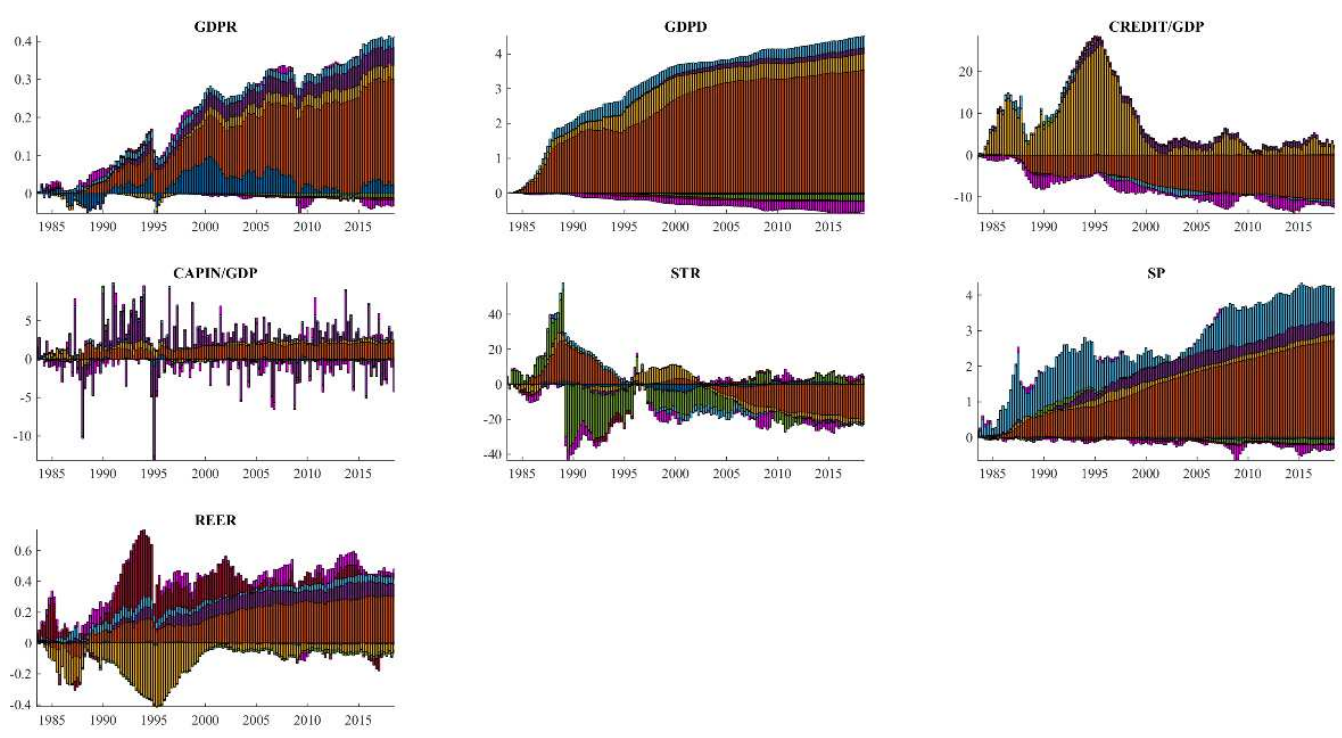

Legend: blue - GDPR, orange - GDPD, yellow - credit/GDP, purple - capital inflows/GDP, green - short term rate, light blue - stock prices, red - REER, pink - uncertainty. 
Figure 17: Historical decomposition for Russia

a) Financial uncertainty shock
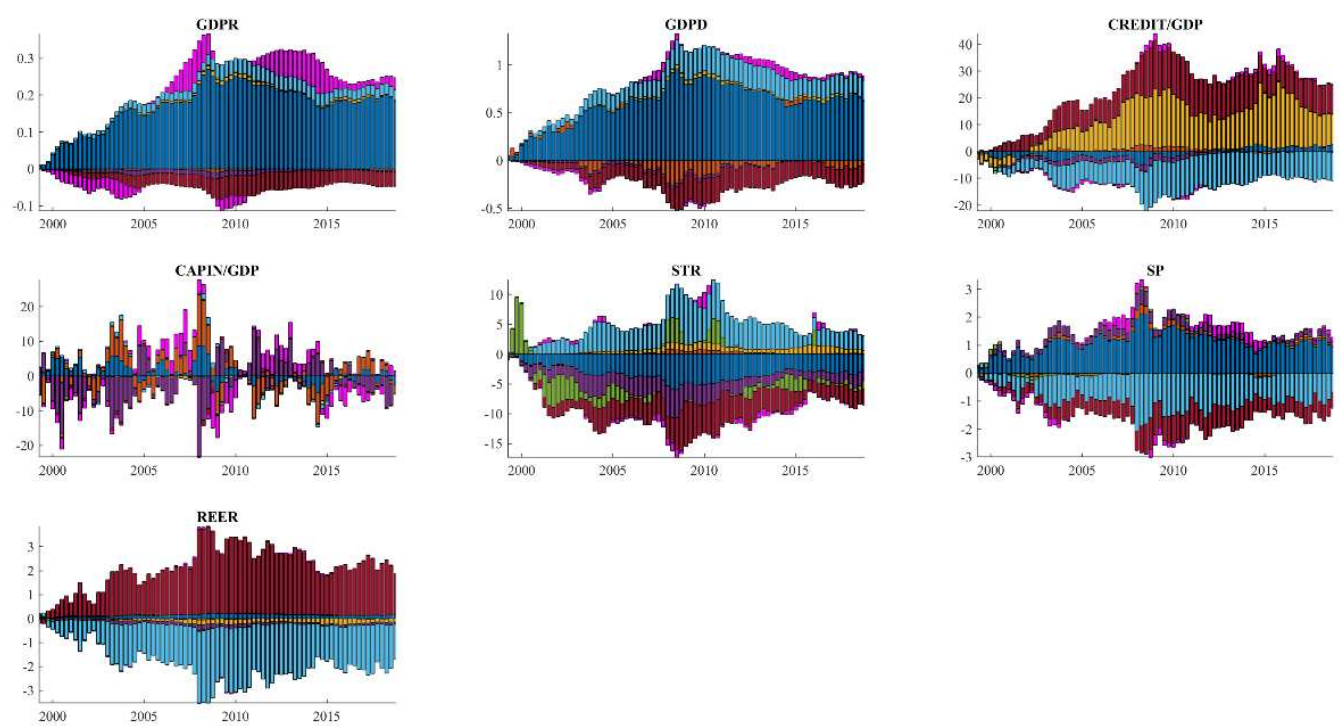

b) Macroeconomic uncertainty shock
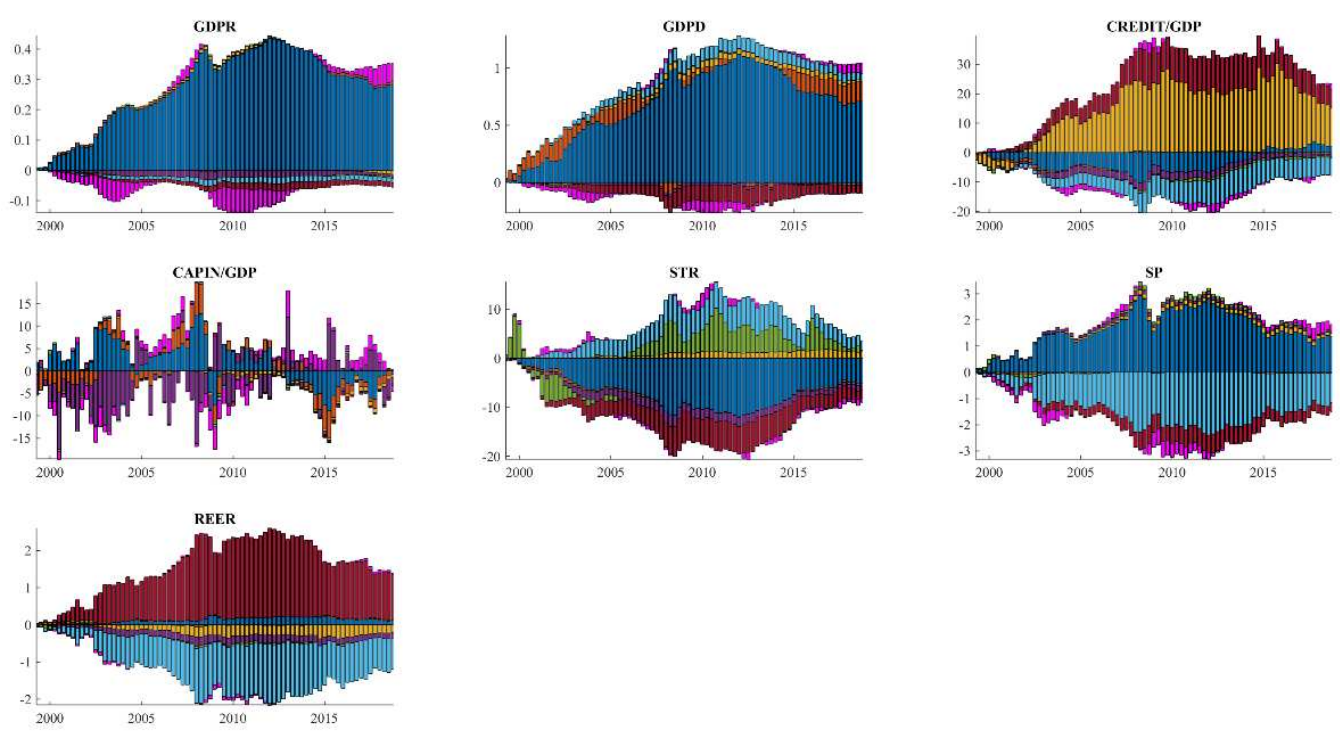

Legend: blue - GDPR, orange - GDPD, yellow - credit/GDP, purple - capital inflows/GDP, green - short term rate, light blue - stock prices, red - REER, pink - uncertainty. 
Figure 18: Historical decomposition for South Africa

a) Financial uncertainty shock
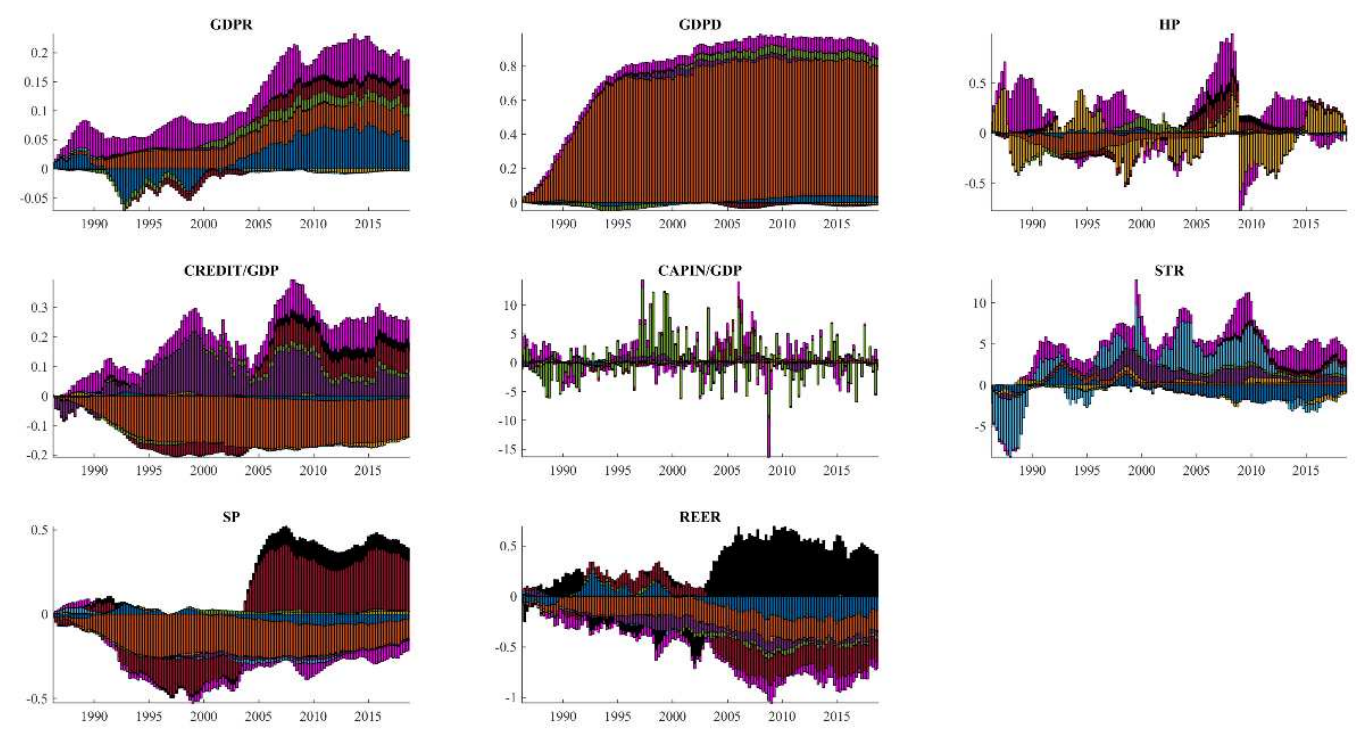

b) Macroeconomic uncertainty shock
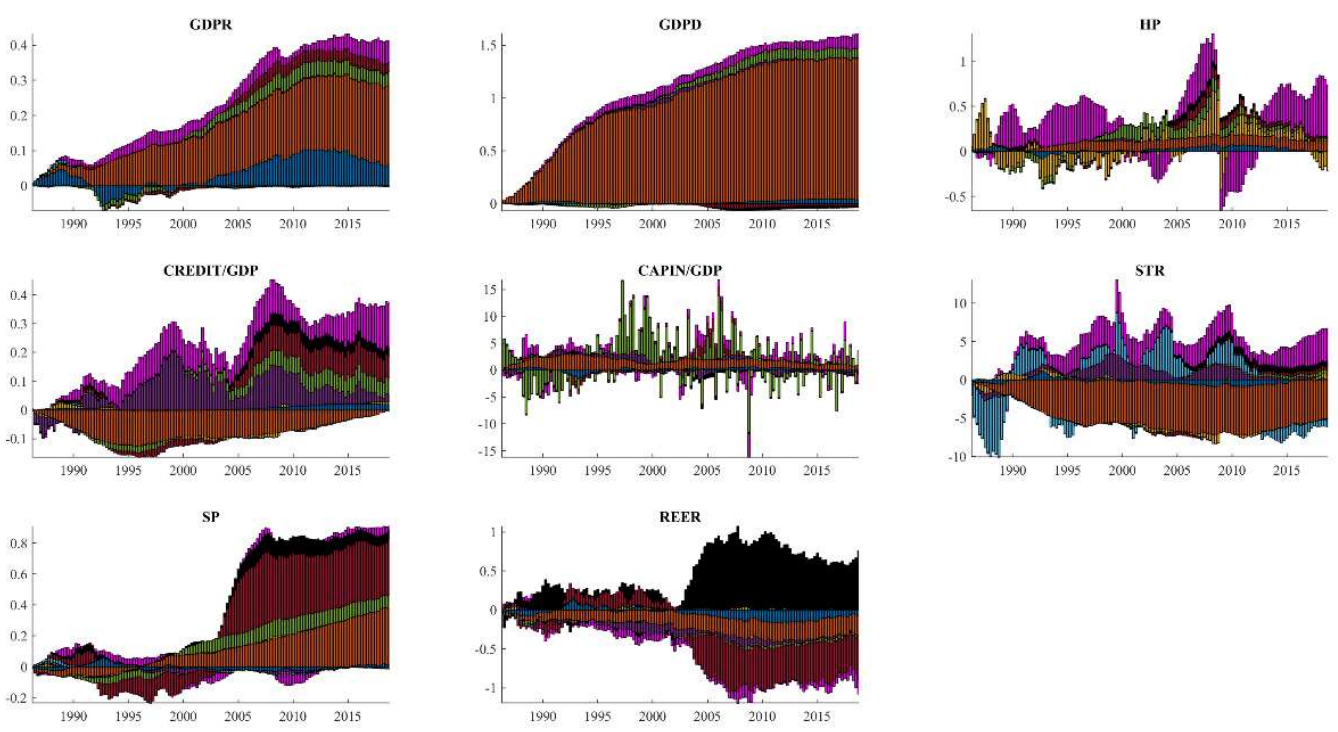

Legend: blue - GDPR, orange - GDPD, yellow - house prices, purple - credit/GDP, green - capital inflows/GDP, light blue - short term rate, red - stock prices, black - REER, pink - uncertainty. 
Figure 19: Historical decomposition for Turkey

a) Financial uncertainty shock
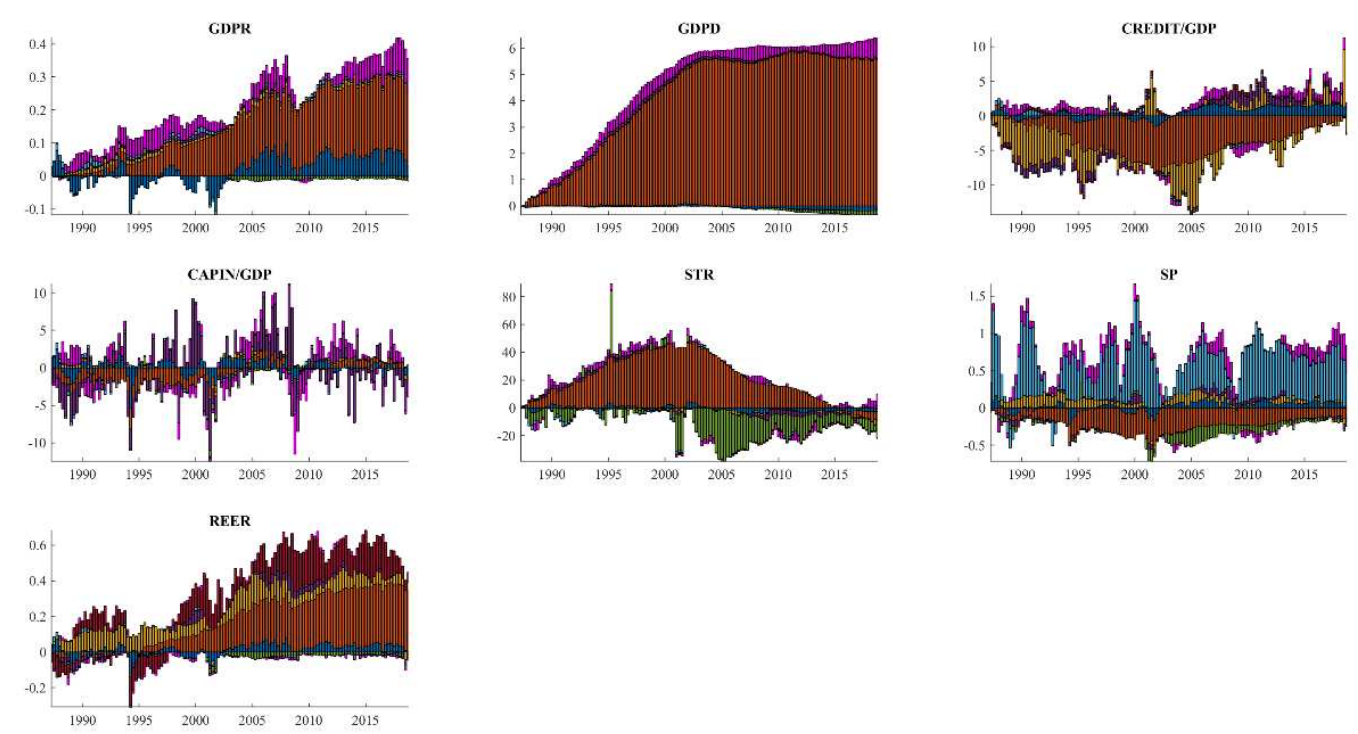

b) Macroeconomic uncertainty shock
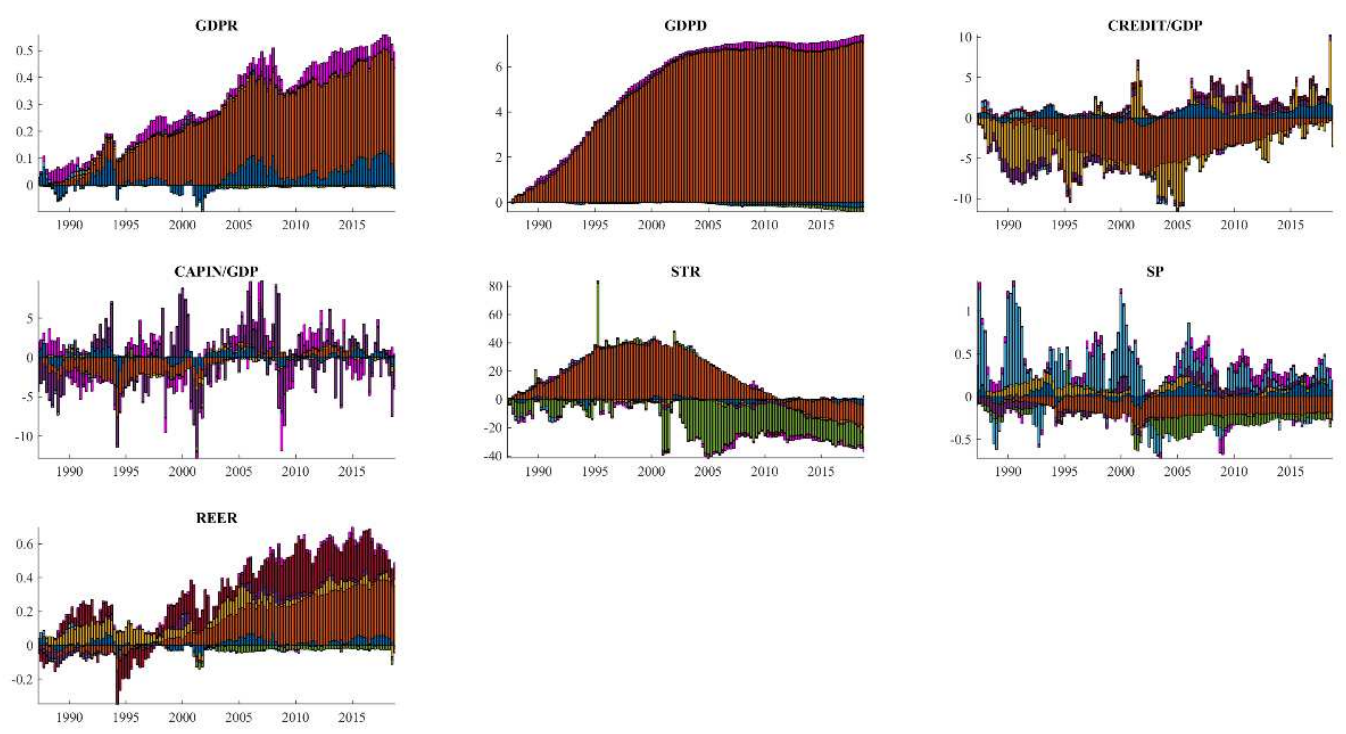

Legend: blue - GDPR, orange - GDPD, yellow - credit/GDP, purple - capital inflows/GDP, green - short term rate, light blue - stock prices, red - REER, pink - uncertainty. 
Table 1: Data summary

\begin{tabular}{|l|c|c|c|c|c|c|c|c|c|}
\hline \multirow{2}{*}{ COUNTRIES } & SAMPLE & Real GDP & $\begin{array}{c}\text { GDP } \\
\text { deflator }\end{array}$ & $\begin{array}{c}\text { Capital } \\
\text { flows }\end{array}$ & Credit/GDP & $\begin{array}{c}\text { Stock } \\
\text { prices }\end{array}$ & $\begin{array}{c}\text { House } \\
\text { prices }\end{array}$ & $\begin{array}{c}\text { Short term } \\
\text { rate }\end{array}$ & $\begin{array}{c}\text { Real eff } \\
\text { exch rate }\end{array}$ \\
\cline { 2 - 10 } Brazil & $\begin{array}{l}1996 q 1 \\
2018 q 4\end{array}$ & OxE & OxE & $\begin{array}{c}\text { IMF } \\
\text { (BOP) }\end{array}$ & BIS & MSCI & - & $\begin{array}{c}\text { Deposit } \\
\text { IMF(IFS) }\end{array}$ & OECD (MEI) \\
\hline China & $\begin{array}{l}1994 q 2 \\
2018 q 4\end{array}$ & OxE & OxE & - & BIS & $\begin{array}{c}\text { IMF } \\
\text { (IFS) }\end{array}$ & OxE & $\begin{array}{c}\text { Deposit } \\
\text { IMF(IFS) }\end{array}$ & OECD (MEI) \\
\hline $\begin{array}{l}\text { Czech } \\
\text { Republic }\end{array}$ & $\begin{array}{l}1994 q 1 \\
2018 q 4\end{array}$ & OxE & OxE & $\begin{array}{c}\text { IMF } \\
\text { (BOP) }\end{array}$ & BIS & OxE & OxE & $\begin{array}{c}\text { Money } \\
\text { market } \\
\text { IMF(IFS) }\end{array}$ & IMF (IFS) \\
\hline India & $\begin{array}{l}1982 q 2 \\
2018 q 4\end{array}$ & OxE & OxE & $\begin{array}{c}\text { IMF } \\
\text { (BOP) }\end{array}$ & BIS & OxE & - & $\begin{array}{c}\text { Interbank } \\
\text { OECD(MEI) }\end{array}$ & OECD (MEI) \\
\hline Mexico & $\begin{array}{l}1982 q 2 \\
2018 q 3\end{array}$ & $\begin{array}{c}\text { OECD } \\
\text { (QNA) }\end{array}$ & OxE & $\begin{array}{c}\text { IMF } \\
\text { (BOP) }\end{array}$ & BIS & $\begin{array}{c}\text { OECD } \\
\text { (MEI) }\end{array}$ & - & $\begin{array}{c}\text { Deposit } \\
\text { IMF(IFS) }\end{array}$ & OECD (MEI) \\
\hline Russia & $\begin{array}{l}1998 q 1 \\
2018 q 4\end{array}$ & OxE & OxE & $\begin{array}{c}\text { IMF } \\
\text { (BOP) }\end{array}$ & BIS & MSCI & - & $\begin{array}{c}\text { Deposit } \\
\text { IMF(IFS) }\end{array}$ & OECD (MEI) \\
\hline South Africa & $\begin{array}{l}1985 q 1 \\
2018 q 4\end{array}$ & $\begin{array}{c}\text { OECD } \\
\text { (QNA) }\end{array}$ & OxE & $\begin{array}{c}\text { IMF } \\
\text { (BOP) }\end{array}$ & BIS & $\begin{array}{c}\text { IMF } \\
\text { (IFS) }\end{array}$ & BIS & $\begin{array}{c}\text { Deposit } \\
\text { IMF(IFS) }\end{array}$ & IMF (IFS) \\
\hline South Korea & $\begin{array}{l}1982 q 2 \\
2018 q 4\end{array}$ & $\begin{array}{c}\text { OECD } \\
\text { (QNA) }\end{array}$ & OxE & $\begin{array}{c}\text { IMF } \\
\text { (BOP) }\end{array}$ & BIS & $\begin{array}{c}\text { IMF } \\
\text { (IFS) }\end{array}$ & OxE & $\begin{array}{c}\text { Money } \\
\text { market } \\
\text { IMF(IFS) }\end{array}$ & OECD (MEI) \\
\hline Turkey & $\begin{array}{l}1986 q 1 \\
2018 q 4\end{array}$ & $\begin{array}{c}\text { OECD } \\
\text { (QNA) }\end{array}$ & OxE & $\begin{array}{c}\text { IMF } \\
\text { (BOP) }\end{array}$ & BIS & OxE & - & $\begin{array}{c}\text { Deposit } \\
\text { IMF(IFS) }\end{array}$ & OECD (MEI) \\
\hline
\end{tabular}


Table 2. Historical decomposition, summary of contributions (positive/negative). Variables listed in bold display the strongest contributions following U.S. uncertainty shocks.

\begin{tabular}{|c|c|c|}
\hline & U.S. Macro Uncertainty & U.S. Financial Uncertainty \\
\hline Brazil & $\begin{array}{l}\operatorname{GDP}(+/-) \text {, inflation }(+/-) \text {, credit }(+/-), \\
\text { capflows }(+/-) \text {, short rate }(+/-) \text {, stock prices } \\
(+/-), \operatorname{REER}(+/-)\end{array}$ & $\begin{array}{l}\operatorname{GDP}(+/-) \text {, inflation }(+/-) \text {, credit }(+/-) \text {, } \\
\text { capflows }(+/-) \text {, short rate }(+/-) \text {, stock prices } \\
(+/-), \operatorname{REER}(+/-)\end{array}$ \\
\hline China & $\begin{array}{l}\text { Inflation }(+/-) \text {, credit }(-) \text {, short rate }(+) \text {, stock } \\
\text { prices }(+)\end{array}$ & $\begin{array}{l}\text { Inflation }(+/-) \text {, credit }(+) \text {, short rate }(-) \text {, stock } \\
\text { prices }(-)\end{array}$ \\
\hline Czech Republic & $\begin{array}{l}\text { GDP }(+/-) \text {, inflation }(+) \text {, house prices }(+/-) \text {, } \\
\text { credit }(+) \text {, capflows }(+/-) \text {, short rate }(+) \text {, } \\
\operatorname{REER}(+)\end{array}$ & $\begin{array}{l}\text { GDP }(+/-) \text {, house prices }(+/-) \text {, credit }(+/-) \text {, } \\
\text { capflows }(+/-) \text {, short rate }(-) \text {, stock prices } \\
(+/-), \operatorname{REER}(+/-)\end{array}$ \\
\hline India & $\begin{array}{l}\text { credit }(+) \text {, capflows }(+/-) \text {, short rate }(+) \text {, } \\
\text { stock prices }(+/-), \operatorname{REER}(+/-)\end{array}$ & $\begin{array}{l}\text { GDP }(+/-) \text {, inflation }(+/-) \text {, credit }(+/-) \text {, } \\
\text { capflows }(+/-) \text {, short rate }(+/-) \text {, stock prices } \\
(+/-), \operatorname{REER}(+/-)\end{array}$ \\
\hline South Korea & $\begin{array}{l}\text { GDP }(-) \text {, inflation }(+) \text {, house prices }(+/-) \text {, } \\
\text { credit }(+/-) \text {, capflows }(+/-) \text {, short rate }(+) \text {, } \\
\text { stock prices }(+/-) \text {, REER }(+)\end{array}$ & $\begin{array}{l}\text { GDP }(-) \text {, inflation }(-) \text {, house prices }(+/-) \text {, } \\
\text { credit }(+/-) \text {, capflows }(+/-) \text {, short rate }(+) \text {, } \\
\text { stock prices }(+/-) \text {, REER }(+/-)\end{array}$ \\
\hline Mexico & $\begin{array}{l}\text { GDP }(+/-) \text {, inflation }(-) \text {, credit }(-) \text {, capflows } \\
(+/-) \text {, short rate }(+/-) \text {, stock prices }(+/-) \text {, } \\
\operatorname{REER}(+)\end{array}$ & $\begin{array}{l}\text { GDP }(+/-) \text {, credit }(+/-) \text {, capflows }(+/-) \text {, short } \\
\text { rate }(+/-) \text {, stock prices }(+/-) \text {, REER }(+/-)\end{array}$ \\
\hline Russia & $\begin{array}{l}\text { GDP }(+/-) \text {, inflation }(+/-) \text {, credit }(+/-), \\
\text { capflows }(+/-) \text {, short rate }(+/-) \text {, stock prices } \\
(+/-)\end{array}$ & $\begin{array}{l}\text { GDP }(+/-) \text {, inflation }(+/-) \text {, credit }(+/-) \text {, } \\
\text { capflows }(+/-) \text {, short rate }(+/-) \text {, stock prices } \\
(+/-)\end{array}$ \\
\hline South Africa & $\begin{array}{l}\text { GDP }(+) \text {, inflation }(+) \text {, house prices }(+/-) \text {, } \\
\text { credit }(+) \text {, capflows }(+/-) \text {, short rate }(+) \text {, } \\
\text { stock prices }(+/-) \text {, REER }(-)\end{array}$ & $\begin{array}{l}\text { GDP }(+) \text {, inflation }(+) \text {, house prices }(+/-) \text {, } \\
\text { credit }(+) \text {, capflows }(+/-) \text {, short rate }(+) \text {, } \\
\text { stock prices }(-), \operatorname{REER}(-)\end{array}$ \\
\hline Turkey & $\begin{array}{l}\text { GDP }(+) \text {, inflation }(+) \text {, capflows }(+/-) \text {, short } \\
\text { rate }(-) \text {, stock prices }(+/-)\end{array}$ & $\begin{array}{l}\text { GDP }(+) \text {, inflation }(+) \text {, credit }(+/-) \text {, capflows } \\
(+/-) \text {, short rate }(+/-) \text {, stock prices }(+/-)\end{array}$ \\
\hline
\end{tabular}




\section{References}

Ahir H., N. Bloom, and D. Furceri (2018). "The World Uncertainty Index", available at https://nbloom.people.stanford.edu/research.

Ahmed, S., B. Coulibaly and A. Zlate, 2017. "International financial spillovers to emerging market economies: How important are economic fundamentals?". Journal of International Money and Finance, 76, pp. 133-52.

Alessandri P., Mumtaz H. (2019). "Financial regimes and uncertainty shocks". Journal of Monetary Economics, 101, pp. 31-46.

Ammer, J., De Pooter, M., Erceg, C.J., Kamin, S.B. (2016). "International Spillovers of Monetary Policy". Tech. Rep. Board of Governors of the Federal Reserve System (US).

Angelini, G., E. Bacchiocchi, G. Caggiano, and L. Fanelli (2019). "Uncertainty Across Volatility Regimes". Journal of Applied Econometrics, 34(3), pp. 437-455.

Bachmann, R., S. Elstner, and E.R. Sims (2013). "Uncertainty and Economic Activity: Evidence from Business Survey Data". American Economic Journal: Macroeconomics, 5 (2): 217-49.

Baker S.R., Bloom N., Davis S.J. (2016). "Measuring Economic Policy Uncertainty". The Quarterly Journal of Economics, 131(4), pp. 1593-1636.

Bańbura, M., D. Giannone and L. Reichlin (2010). "Large Bayesian vector auto regressions". Journal of Applied Econometrics, 25(1), 71-92.

Basu, S., and B. Bundick (2017). "Uncertainty Shocks in a Model of Effective Demand". Econometrica, 85, 3, 937-958.

Bekaert, G., M. Hoerova and M. Lo Duca, 2013. "Risk, uncertainty, and monetary policy". Journal of Monetary Economics, 6o(7), pp. 771-88.

Bernanke, B.S., M. Gertler, S.Gilchrist (1999). "The financial accelerator in a quantitative business cycle framework". Chapter 21 in Handbook of Macroeconomics, Elsevier, 1C, 1341-1393.

Bhattarai S., Chatterjee A., Park W.Y. (2019). "Global Spillover Effects of US Uncertainty". Journal of Monetary Economics, in press.

Bloom N. (2009). "The impact of uncertainty shocks". Econometrica 77, pp. 623-685.

Bloom, N. (2014). "Fluctuations in uncertainty". Journal of Economic Perspectives, 28, pp. 153-176.

Bonciani, D., and M. Ricci (2018). "The global effects of global risk and uncertainty". European Central Bank Working Paper No. 2179.

Borio, C. (2014). "The financial cycle and macroeconomics: what have we learnt?" Journal of Banking and Finance, vol. 45, 182-98.

Borio, C., H. Zhu (2012). "Capital regulation, risk-taking and monetary policy: A missing link in the transmission mechanism?" Journal of Financial Stability, 8, 236-251.

Bruno, V. H.S. Shin (2015). "Capital flows and the risk-taking channel of monetary policy". Journal of Monetary Economics, 71,119-132.

Bua, G., and C. Trecroci (2019). "International Equity Markets Interdependence: Bigger Shocks or Contagion in the 21st Century?" Review of World Economics, 155(1), 43-69.

Caldara D., Fuentes-Albero C., Gilchrist S., Zakrajzek E. (2016). "The macroeconomic impact of financial and uncertainty shocks". European Economic Review, 88, pp. 185-207. 
Caggiano, G. E. Castelnuovo, J.M. Figueres (2014). "Economic policy uncertainty and unemployment in the United States: A nonlinear approach". Economics Letters, 151, 31-34.

Caggiano, G., E. Castelnuovo, and J. M. Figueres (2019). "Economic Policy Uncertainty Spillovers in Booms and Busts". Oxford Bulletin of Economics and Statistics, forthcoming.

Caldara, D., C. Fuentes-Albero, S. Gilchrist and E. Zakrajsek (2018). "The macroeconomic impact of financial and uncertainty shocks". European Economic Review, 88(C), 185-207.

Carriere-Swallow Y., Cespedes L.F. (2013). "The Impact of Uncertainty Shocks in Emerging Economies". Journal of International Economics, 90, pp. 316-325.

Carriero A., Mumtaz H., Theodoridis K., Theophilopoulou A. (2015). "The Impact of Uncertainty Shocks under Measurement Error: A Proxy SVAR Approach". Journal of Money, Credit and Banking, 47(6), pp. 12231238.

Carriero A., Clark T.E., Marcellino M. (2018a). "Measuring Uncertainty and its Impact on the Economy," Review of Economics and Statistics, 100(5), pp. 799-815.

Carriero A., Clark T.E., Marcellino M. (2018b). "Endogenous Uncertainty". Working paper n. 1805, Federal Reserve Bank of Cleveland.

Castelnuovo, E. (2019). "Domestic and Global Uncertainty: A Survey and Some New Results". CESifo Working Paper \#7900.

Cerutti, E., S. Claessens and A.K. Rose, 2019. "How Important is the Global Financial Cycle? Evidence from Capital Flows," IMF Economic Review, vol 67(1), pages 24-60.

Cesa-Bianchi, A., M. H. Pesaran and A. Rebucci (2019). "Uncertainty and Economic Activity: A Multicountry Perspective". Forthcoming, Review of Financial Studies.

Choi S. (2017). "Variability in the effects of uncertainty shocks: new stylized facts from OECD countries". Journal of Macroeconomics, 53, pp 127-144.

Choi S. (2018). "The impact of US financial uncertainty shocks on emerging market economies: an international credit channel". Open Economies Review, 29, pp. 89-118.

Christiano, L.J., R. Motto, and M. Rostagno (2014). "Risk Shocks". American Economic Review, 104 (1): 27-65. Coimbra, N., and H. Rey (2018). "Financial Cycles and Credit Growth across Countries". AEA Papers and Proceedings, 108, 509-12.

Colombo, V. (2013). "Economic policy uncertainty in the US: Does it matter for the Euro Area?". Economics Letters, 121(1), pp 39-42.

Cuaresma, J.C., F. Huber and L. Onorante (2020). "Fragility and the effect of international uncertainty shocks". Forthcoming, Journal of International Money and Finance.

Dedola L., Rivolta G., and Stracca L. (2017). "If the Fed sneezes, who catches a cold?". Journal of International Economics, 108, pp. S23-S41.

Gertler, M., and Peter Karadi (2015). "Monetary Policy Surprises, Credit Costs, and Economic Activity". American Economic Journal: Macroeconomics, 7 (1): 44-76.

Giannone, D., M. Lenza, and G. E. Primiceri (2015). "Prior Selection for Vector Autoregressions". Review of Economics and Statistics, 97, 436-451.

Gilchrist, S., and E. Zakrajšek (2012). "Credit Spreads and Business Cycle Fluctuations". American Economic Review, 102 (4): 1692-1720.

Gourinchas, P.O. and H. Rey (2017). "Exorbitant Privilege and Exorbitant Duty". Technical report, London Business School and UC Berkeley. 
Gourinchas, P.O., H. Rey and M. Sauzet (2019). "The International Monetary and Financial System". Annual Review of Economics, forthcoming.

lacoviello, M., and G. Navarro (2019). "Foreign Effects of Higher U.S. Interest Rates". Journal of International Money and Finance, 95, 232-250.

Jorda, O., M. Schularick, A.M. Taylor, and F. Ward (2019). "Global Financial Cycles and Risk Premiums". IMF Economic Review, 67, 109-150.

Jurado K.,Ludvigson S.C., Ng S. (2015) ."Measuring uncertainty". American Economic Review, 105, pp. 11771216.

Koop G., Pesaran M.H., Potter M. (1996). "Impulse response analysis in nonlinear multivariate models". Journal of Econometrics, 74, pp. 119-147.

Kiyotaki, N. and J. Moore (2019). "Liquidity, Business Cycles, and Monetary Policy". Journal of Political Economy, ahead of print.

Knight, F. H. (1921). "Risk, Uncertainty, and Profit". Houghton Mifflin Company, Hart, Schaffner \& Marx, Boston, MA.

Leduc, S. and Z. Liu (2016). "Uncertainty shocks are aggregate demand shocks". Journal of Monetary Economics, 82, 20-35.

Ludvigson, S.C., Ma S., Ng S., (2019). "Uncertainty and Business Cycles: Exogenous Impulse or Endogenous Response?" American Economic Journal: Macroeconomics, forthcoming.

Mehrotra, A., R. Moessner and C. Shu (2019). "Interest rate spillovers from the United States: expectations, term premia and macro-financial vulnerabilities". BIS Working Papers No 814.

Mendoza, E.G., (2010). "Sudden Stops, Financial Crises, and Leverage". American Economic Review, 100 (5): 1941-66.

Miranda-Agrippino, S., and H. Rey (2020). "The Global Financial Cycle After Lehman". Forthcoming AEA Papers \& Proceedings.

Obstfeld, m. (2020). "Global Dimensions of U.S. Monetary Policy". Forthcoming, International Journal of Central Banking.

Pesaran M.H., Shin Y. (1998). "Generalized impulse response analysis in linear multivariate models". Economic Letters, 58, pp. 17-29.

Piffer, M. and M. Podstawski (2018). "Identifying Uncertainty Shocks Using the Price of Gold". Economic Journal, 128, 616, 3266-3284

Popp A., Zhang F., (2016). "The macroeconomic effects of uncertainty shocks: the role of the financial channel". Journal of Economic Dynamics and Control, 69, pp. 319-349.

Redl, C. (2020). "Uncertainty matters: evidence from close elections". Journal of International Economics, in press, https://doi.org/10.1016/j.jinteco.2020.103296.

Rey, H., (2015). "Dilemma not trilemma: the global financial cycle and monetary policy independence". NBER Working Papers \# 21162.

Shin, H.S. (2102). "Global banking glut and loan risk premium". Mundell-Fleming Lect., IMF Econ. Rev., 60 (2), 155-192.

Stock, James H., and Mark W. Watson. (2018). "Identification and Estimation of dynamic causal effects in macroeconomics using external instruments". The Economic Journal, 128, pp. 917-948 